\title{
NONLINEAR TIME-DOMAIN SOIL-STRUCTURE INTERACTION ANALYSIS OF EMBEDDED REACTOR STRUCTURES SUBJECTED TO EARTHQUAKE LOADS
}

\author{
Jerome M. Solberg ${ }^{1,2}$, Quazi Hossain ${ }^{3}$, George Mseis ${ }^{4,5}$ \\ ${ }^{1}$ Methods Development Group, Lawrence Livermore Nat'1 Lab, P.O. Box 808, Mailstop L-125, \\ Livermore, CA, USA, 94550, solberg2@1lnl.gov \\ ${ }^{2}$ Corresponding author \\ ${ }^{3}$ Structural and Applied Mechanics Group, Lawrence Livermore Nat'l Lab, P.O. Box 808, Mailstop L- \\ 129, Livermore, CA, USA, 94550, hossain1@1lnl.gov \\ ${ }^{4}$ Structural and Applied Mechanics Group, Lawrence Livermore Nat'1 Lab, P.O. Box 808, Mailstop L- \\ 129, Livermore, CA, USA, 94550 \\ ${ }^{5}$ Present address: Total New Energies USA, EmeryStation 1, 5858 Horton Street, Suite 253, Emeryville, \\ CA 94608, george.mseis@ gmail.com
}

\begin{abstract}
A generalized time-domain method for Soil-Structure Interaction Analysis is developed, based upon an extension of the work of the domain reduction method of Bielak, et. al.. The methodology is combined with the use of a simple hysteretic soil model based upon the Ramberg-Osgood formulation and applied to a notional Small Modular Reactor. These benchmark results compare well (with some caveats) with those obtained by using the industry-standard frequency-domain code SASSI. The methodology provides a path forward for investigation of other sources of nonlinearity, including those associated with the use of more physically-realistic material models incorporating pore-pressure effects, gap opening/closing, the effect of nonlinear structural elements, and 3D seismic inputs.
\end{abstract}

Keywords: soil-structure interaction, SASSI, seismic analysis, nonlinear time domain, Ramberg-Osgood, Domain Reduction Methods.

\section{INTRODUCTION}

For over 30 years, modeling of nuclear power reactors for seismic safety has been conducted using a simplified soil-structure interaction (SSI) analysis approach that has proven remarkably powerful given the then available knowledge of the response of structures, soils, and their interactions under the cyclical loading of seismic shaking. This analysis approach is exemplified by the computer program SASSI, which has been subject to continuous improvement since its introduction in the early 1980's, documented in Ostadan (2007). However, many of the inherent limitations of the overall approach remain.

Technology related to earthquake rupture, seismic wave propagation, structural mechanics, and soil models have all advanced enormously since the early eighties, grounded substantially on the rapid advance in computing power. Much more robust models are now available to address each part of power reactor seismic response (source to site) and to address all of the relevant physics including nonlinear features of site and structure response. Given recent events in which nuclear power reactors have been subjected to beyond-design seismic shaking, as well as the emergence of advanced reactor designs, an important and urgent question is whether a coherent new approach incorporating advanced nonlinear models and modeling techniques using high performance computing can predict nuclear reactor response to earthquakes with higher fidelity than standard techniques in current use.

Given this motivation, this work develops a generalized time-domain method for soil-structure interaction, based upon an extension of the domain reduction method originally developed by Bielak and 
coworkers, with more details in Bielak, Loukakis, Hisada and Yoshimura (2003). The methodology was combined with a simple hysteretic model based on the 1-D Ramberg-Osgood formulation and utilized to model the response of a notional Small Modular Reactor (SMR) and incorporated into the parallel implicit multiphysics finite element code DIABLO, documented in Solberg, et. al.(2014). DIABLO was then used to simulate synthesized earthquakes with nominal magnitudes from $0.2 \mathrm{~g}$ to $0.9 \mathrm{~g}$ applied to the structure. The results expressed in terms of response spectra at selected points on the structure compare favorably with those produced by SASSI. Because of the use of a general nonlinear time-domain formulation, the methodology provides a path forward for investigation of other sources of nonlinearity, including those associated with more physically-realistic material models incorporating pore-pressure effects, gap opening/closing, the effect of nonlinear structural elements, and 3D seismic inputs. This paper is a summary of work which is covered more comprehensively in a report authored by Solberg, Hossain, Blink, Bohlen, Mseis and Greenberg (2013) which is accessible through the LLNL library with reference number LLNL-TR-635762.

\section{THE NEED FOR NON-LINEAR TIME DOMAIN ANALYSES}

The current approach as represented by the computer code SASSI solves the equations of motion in the frequency-domain. Such an approach is inherently limited to linear representation of soil properties as it relies on the principle of superposition. Soils are strongly nonlinear even at small strains, featuring both strain-dependent stiffness and strain-dependent damping characteristics, as documented for example in the EPRI report on strain-dependent soil characteristics, EPRI (1993) and Figure 1. SASSI can incorporate these strain dependencies only indirectly, via the equivalent-linear approach, illustrated in Figure 2. Soils typically exhibit stiffness and damping properties that are significantly affected by changes in three-dimensional confining pressures as the seismic event progresses, documented in Zhang, Andrus and Juang (2005). Many soils typically exhibit significant evolution of the soil response over a number of strain cycles, often in concert with pore water pressure and content evolution, as in Matasovic and Vucetic (1993). The current SASSI approach is not capable of incorporating these latter two effects, even indirectly.

In the equivalent-linear method used by SASSI, the maximum strains as a function of vertical position in the soil column are estimated for a specified seismic input via a 1D soil column solution (without the structure) performed by a code such as SHAKE, documented in Idriss, Sun, Schnabel, Lysmer, and Seed (1992) or CARES, documented in Costantino, Miller and Xu (1995). Constant stiffness and damping values are selected for each soil layer based upon this prediction and utilized in the SASSI calculation. This method may be non-conservative in a number of cases:

- The equivalent-linear approach may overpredict the soil impedance in regions/time periods with low (but significant) amplitude response, as often occurs at higher frequencies, for instance see the discussion in Assimaki and Kausel (2002). This is because a single damping and modulus value is used for the soil layer throughout the analysis, which means that input motions with high frequency/low amplitude are subject to higher damping and lower modulus soil behavior than is physically expected.

- The equivalent-linear approach may underpredict the soil deformation (and hence underpredict the soil impedance) at locations of local stress concentrations caused by the structure/soil interface, where softening in excess of that predicted in the simple 1-D preprocessing step may occur, as discussed in Bonilla, Archuleta and Lavallee (2005).

- The equivalent-linear approach cannot account for the pressure dependence of soils as discussed in Zerfa and Loret (2003). This effect that is particularly important in the presence of "raft uplift", which may occur under portions of the basemat during rocking motions, more information may be found in Wolf and Song (2002), and hence may contribute to modified structural response. 
- The "hysteretic damping" used in equivalent-linear analyses for the soil model, although perhaps better able to model certain experimental results than simple Kelvin-Vogt models typically used in linear time-domain analysis, is mathematically suspect since it cannot be transformed to a causal function in the time-domain, as discussed in Crandall (1970).

- Equivalent-linear analyses cannot account for geometric nonlinearity resulting from separation (contact/release) at the interface between the soil and the structure during a seismic event, which may result in markedly different local wave propagation characteristics, and thereby significantly affect the structural response.

In contrast, time-domain analysis is capable of routinely modeling fully nonlinear soils with straindependent soil stiffness properties and can easily account for geometric nonlinearity resulting from gap closing/separation at the interface of the soil and structure. It is important to note that because of the granular, frictional nature of soils, accurate models of soil response require nonlinear behavior even at near-zero strains, as discussed in the work of Drosos, Gerolymos and Gazetas (2012). In recent years, nonlinear models have been developed which can adequately model the hysteretic behavior of soils in the time domain. In advanced versions, such features as pressure dependence and cyclic degradation have been included, as discussed in the work of Soga and O'Sullian (2010).
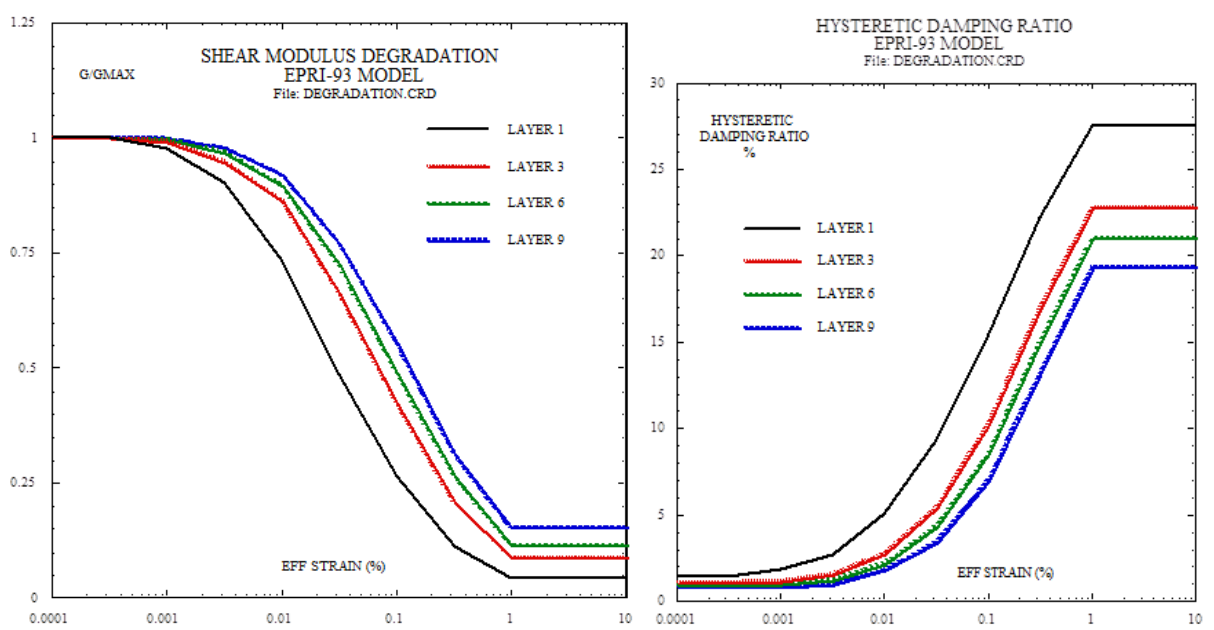

Figure 1 - Typical Shear Modulus Degradation and Damping Curves 


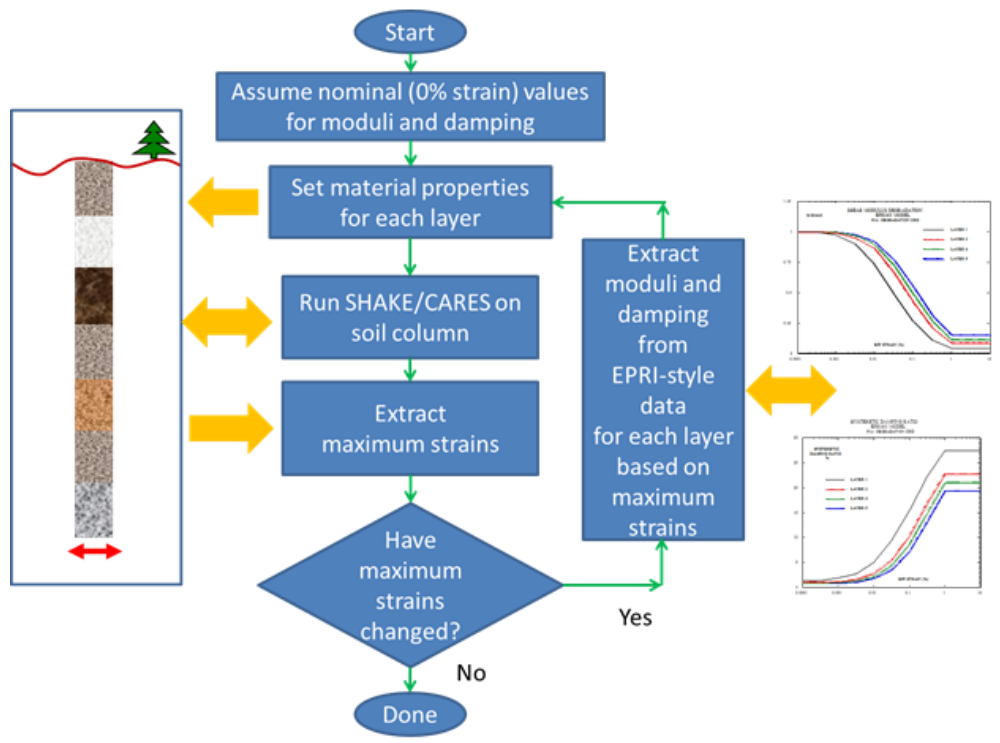

Figure 2 - Calculation of Equivalent-Linear Properties

\section{THE DOMAIN REDUCTION METHOD OF BIELAK AND ITS EXTENSION TO NONLINEAR MATERIALS}

To develop a state-of-the-art nonlinear time-domain SSI analysis method our work extended the domain reduction method developed by Bielak and coworkers, documented in Bielak, Loukakis, Hisada and Yoshimura (2003). This methodology provides a means for applying seismic input motion which avoids the use of absorbing boundary conditions ${ }^{1}$. Since absorbing boundary conditions are by their nature dependent on linear material response, their use in nonlinear analysis is problematic. The domain reduction method of Bielak and coworkers consists of two primary steps:

1) Partition the soil around the building into three regions, $\Omega_{I}$ (the inner region immediately around the building), $\Omega_{\mathrm{II}}$ (the outer region that prevents wave reflection), and $\Omega_{\mathrm{III}}$ (the intermediate region), as illustrated in Figure 3.

2) Drive the inner region $\Omega_{\mathrm{I}}$ according to a prescribed seismic input time history, through forces applied in the intermediate region $\Omega_{\mathrm{III}}$. Assuming the seismic input time history is consistent with the discrete solution in $\Omega_{\mathrm{I}}$ (absent the structure), the motion in the outer region $\Omega_{\mathrm{II}}$ consists only of the waves scattered by the presence of the structure.

This algorithm has the following key features:

1) Knowledge of the free-field motion is needed only in a small subset of the problem, in this case the region $\Omega_{\mathrm{III}}$.

2) In the absence of the structure, the exact solution for the seismic wave is reproduced within $\Omega_{\mathrm{I}}$ and zero displacement is recovered within $\Omega_{\text {II }}$ (assuming the seismic input corresponds to the exact solution for a seismic wave within $\Omega_{\mathrm{II}}$ ).

3) The need for a high-performance absorbing boundary is greatly reduced, since

a. One particular method of producing seismic input consists of an absorbing boundary condition "driven backwards" to produce a wave propagating inwards, with amplitudes corresponding to the strength of the simulated earthquake. As the seismic input is applied using another technique, the need for the absorbing boundary condition to operate correctly at all earthquake magnitudes is eliminated.

\footnotetext{
${ }^{1}$ Strictly speaking, absorbing boundary conditions are used in the domain reduction method at the outer boundary of $\Omega^{+}$, but they need not work hard or be very accurate since they are not required to drive the primary motion or absorb the full incident wave.
} 
b. The only waves that propagate within $\Omega_{\text {II }}$ are the scattered waves, which are of significantly reduced magnitude in comparison to the seismic input.

c. As the material response within $\Omega_{\mathrm{II}}$ may include dissipation, and as a result of geometric attenuation, the magnitude of the scattered waves by the time they reach the outer boundary is small, even when compared with the magnitude at the structure (the source of the scattered waves).

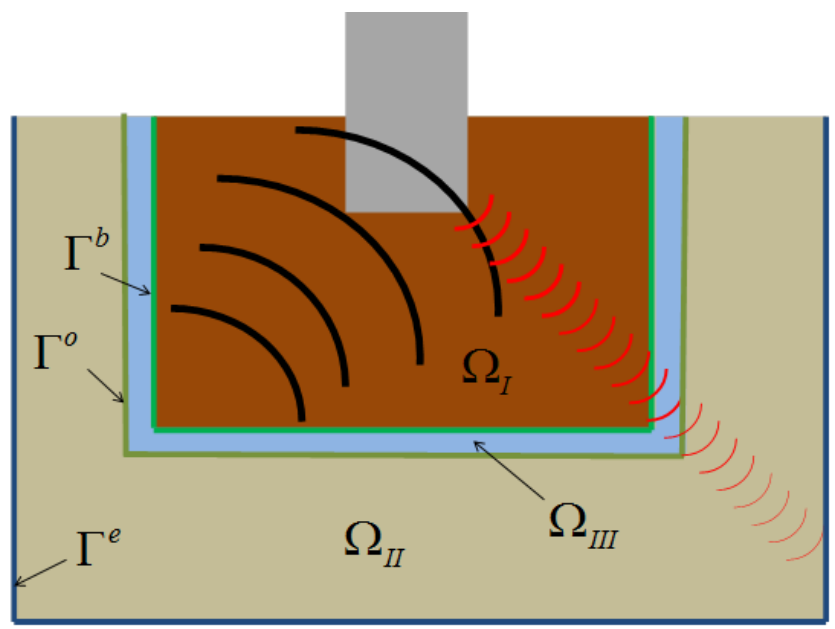

Figure 3 - The Domain Reduction Method of Bielak, et. al.

The domain reduction method developed by Bielak assumes the existence of an exact solution $\mathbf{u}=\overline{\mathbf{u}}(\mathbf{x}, t)$ for the displacement $\mathbf{u}$ in a free-field wave propagation problem as a function of position $\mathbf{x}$ and time $t$. Via standard kinematics, the symmetric small strain tensor $\nabla^{s} \overline{\mathbf{u}}$ and its time derivative $\nabla^{s} \dot{\overline{\mathbf{u}}}$ are also known throughout the domain as a function of time and position. Through the constitutive relation of the material, an exact solution for the Cauchy stress $\boldsymbol{\sigma}=\overline{\boldsymbol{\sigma}}(\mathbf{x}, t)$ results, as detailed in Equation 1 .

$$
\begin{aligned}
& \mathbf{u}=\overline{\mathbf{u}}(\mathbf{x}, t) \Rightarrow \dot{\mathbf{u}}=\dot{\overline{\mathbf{u}}}(\mathbf{x}, t) \Rightarrow \ddot{\mathbf{u}}=\ddot{\overline{\mathbf{u}}}(\mathbf{x}, t) \\
& \boldsymbol{\sigma}=\boldsymbol{\sigma}\left(\nabla^{s} \overline{\mathbf{u}}, \nabla^{s} \dot{\overline{\mathbf{u}}}\right) \Rightarrow \boldsymbol{\sigma}=\overline{\boldsymbol{\sigma}}(\mathbf{x}, t)
\end{aligned}
$$

In the methodology as originally developed, the region $\Omega_{\mathrm{III}}$ is assumed one element thick. Therefore, the nodes associated with elements in $\Omega_{\mathrm{III}}$ fall into two categories, those associated with the "seismic input" boundary $\Gamma^{b}$, and those associated with the boundary with $\Omega_{\mathrm{II}}, \Gamma^{0}$ as in Figure 3 . Construct a smooth non-negative scalar function $B(\mathbf{x})$ with value 1 on $\Gamma^{b}$ and value 0 on $\Gamma^{0}$ (Equation 2):

$$
B(\mathbf{x}):=\left\{\begin{array}{l}
1 \forall \mathbf{x} \in \Gamma^{b} \\
0 \forall \mathbf{x} \in \Gamma^{0}
\end{array}\right.
$$

The scaling function is used to produce a scaled solution $\tilde{\mathbf{u}}(\mathbf{x}, t)$ and the resulting Cauchy Stress $\tilde{\boldsymbol{\sigma}}(\mathbf{x}, t)$ within $\Omega_{\text {III }}$, Equation 3:

$$
\begin{aligned}
& \tilde{\mathbf{u}}(\mathbf{x}, t)=\beta(\mathbf{x}) \overline{\mathbf{u}}(\mathbf{x}, t) \\
& \tilde{\boldsymbol{\sigma}}=\boldsymbol{\sigma}\left(\nabla^{s} \tilde{\mathbf{u}}, \nabla^{s} \dot{\tilde{\mathbf{u}}}\right)=\tilde{\boldsymbol{\sigma}}(\mathbf{x}, t)
\end{aligned}
$$


For nodes with (vector) shape function $\mathbf{N}^{\text {node }}$ that are located on $\Gamma^{0}$, or entirely within the region $\Omega_{\mathrm{III}}$, the vector of nodal forces $\mathbf{F}_{\text {node }}$ due to the scaled solution are subtracted from the current solution. For nodes that are located in $\Gamma_{b}$, the nodal forces $[\mathbf{F}]_{\text {node }}$ due to the scaled solution are subtracted, and then those from the exact solution are added (as evaluated within $\Omega_{\mathrm{III}}$ ). In other words, the nodal forces resulting from elements within $\Omega_{\mathrm{III}}$ are calculated according to Equation 4:

$$
\mathbf{F}_{n o d e}=\left\{\begin{array}{c}
-\int_{\Omega_{I I}}\left((\boldsymbol{\sigma}-\tilde{\boldsymbol{\sigma}}) \bullet \nabla^{S}\left[\mathbf{N}^{\text {node }}\right]+\rho(\ddot{\mathbf{u}}-\ddot{\tilde{\mathbf{u}}}) \bullet \mathbf{N}^{\text {node }}\right) d \Omega \mid \\
-\left.\int_{\Omega_{I I}}\left((\boldsymbol{\sigma}-\tilde{\boldsymbol{\sigma}}+\overline{\boldsymbol{\sigma}}) \bullet \nabla^{S}\left[\mathbf{N}^{\text {node }}\right]+\rho(\ddot{\mathbf{u}}-\ddot{\tilde{\mathbf{u}}}+\ddot{\overline{\mathbf{u}}}) \bullet \mathbf{N}^{\text {node }}\right) d \Omega\right|_{\text {node IS located on located on } \Gamma^{b}}
\end{array}\right.
$$

Appendix I demonstrates how these equations are related to the domain reduction method of Bielak and coworkers in detail. In short, however, assume the materials are linear. In this case one can write

$$
\mathbf{F}_{\text {node }}=\left\{\begin{array}{c}
-\left.\int_{\Omega_{I I}}\left(\mathbf{C}\left(\nabla^{S} \mathbf{u}-\nabla^{S} \tilde{\mathbf{u}}\right) \bullet \nabla^{S}\left[\mathbf{N}^{\text {node }}\right]+\rho(\ddot{\mathbf{u}}-\ddot{\tilde{\mathbf{u}}}) \bullet \mathbf{N}^{\text {node }}\right) d \Omega\right|_{\text {node is NOT located on } \Gamma^{b}} \\
-\left.\int_{\Omega_{I I}}\left(\mathbf{C}\left(\nabla^{S} \mathbf{u}-\nabla^{S} \tilde{\mathbf{u}}+\nabla^{S} \overline{\mathbf{u}}\right) \bullet \nabla^{S}\left[\mathbf{N}^{\text {node }}\right]+\rho(\ddot{\mathbf{u}}-\ddot{\tilde{\mathbf{u}}}+\ddot{\overline{\mathbf{u}}}) \bullet \mathbf{N}^{n o d e}\right) d \Omega\right|_{\text {node IS located on } \Gamma^{b}}
\end{array}\right.
$$

Now assume that the intermediate layer is one element thick. In this case, there are no nodes in the interior of $\Omega_{\text {III. }}$ Linearization of these equations produces equation (8) of Bielak, Loukakis, Hisada and Yoshimura (2003). In the absence of scattered waves from the structure, the following solution (Equation 5 ) is recovered, where it is noted that the solution is zero in the external region $\Omega_{I I}$

$$
\mathbf{u}(x, t)=\left\{\begin{array}{c}
\overline{\mathbf{u}}(\mathbf{x}, t) \forall \mathbf{x} \in \Omega_{I} \\
\tilde{\mathbf{u}}(\mathbf{x}, t) \forall \mathbf{x} \in \Omega_{I I I} \\
\mathbf{0} \forall \mathbf{x} \in \Omega_{I I}
\end{array} \Rightarrow \boldsymbol{\sigma}(x, t)=\left\{\begin{array}{c}
\overline{\boldsymbol{\sigma}}(\mathbf{x}, t) \forall \mathbf{x} \in \Omega_{I} \\
\tilde{\boldsymbol{\sigma}}(\mathbf{x}, t) \forall \mathbf{x} \in \Omega_{I I I} \\
\mathbf{0} \forall \mathbf{x} \in \Omega_{I I}
\end{array}\right.\right.
$$

If scattered waves are generated by the structure, they will perturb the solution everywhere, thus inducing non-zero solutions within $\Omega_{\mathrm{II}}$. However, the scattered waves will be generally significantly smaller in magnitude than the incident waves. In addition, because of material dissipation and geometric attenuation, by the time these waves reach the external boundary, their magnitude will be reduced further. Hence the absorbing boundary condition need not be exceptionally effective at attenuating reflections at the external boundary.

Bielak and coworkers developed their original method for linear materials in matrix form, assuming the intermediate region is one element thick. Equation 5 recovers the Bielak solution for linear materials, but is valid equally for non-linear materials and for an intermediate region which is more than one element thick, assuming the scaling function $B(\mathbf{x})$ defined in Equation 2 is defined smoothly within the interior of $\Omega_{\text {IIII }}$. However, an additional modification to the method is necessary for nonlinear materials. A nonlinear material has variable impedance (the tangent modulus varies as a function of strain level and strain history). For soils, the impedance at large strains is typically lower than the impedance at zero strain. In order to ensure that waves reflected by the structure do not reflect at the layer boundaries, the impedance within $\Omega_{\mathrm{III}}$ should vary smoothly from the high-impedance value of the 
undisturbed soil in $\Omega_{\mathrm{II}}$ to the low-impedance value of the highly strained soil within $\Omega_{\mathrm{I}}$. This principle is illustrated in Figure 4.

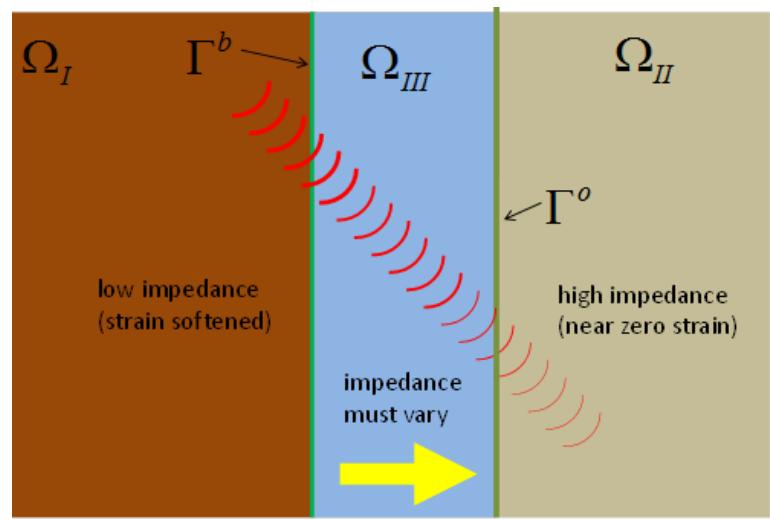

Figure 4 - Required variation of impedance within the intermediate region

Unfortunately, the strain which is developed within $\Omega_{\mathrm{III}}$ by the scaled solution of Equation 3 does not lead to smoothly varying impedance, as the strain contains an extra term due to the gradient of $\beta(\mathbf{x})$, that is

$$
\begin{aligned}
& \tilde{\mathbf{u}}(\mathbf{x}, t)=\beta(\mathbf{x}) \overline{\mathbf{u}}(\mathbf{x}, t) \\
& \Rightarrow \nabla^{s} \tilde{\mathbf{u}}=\beta(\mathbf{x}) \nabla^{s} \overline{\mathbf{u}}+(\overline{\mathbf{u}} \otimes \nabla \beta)^{S}
\end{aligned}
$$

The extra term leads to increased strain (and stress) in the intermediate layer, which may lead to deleterious effects. To first order, the impedance may suffer a jump at the interfaces $\Gamma^{b}$ and $\Gamma^{0}$. More seriously, more complex material models (incorporating, for example, pressure dependency) may fail if the material experiences tension - which may be induced by this second term. Therefore, the following modification to the strain and strain rate is used within the intermediate layer:

$$
\begin{aligned}
& \hat{\mathbf{\varepsilon}}\left(\nabla^{s} \mathbf{u}\right)=\nabla^{s} \mathbf{u}(\mathbf{x}, t)-(\overline{\mathbf{u}} \otimes \nabla \beta)^{s} \\
& \dot{\hat{\boldsymbol{\varepsilon}}}\left(\nabla^{s} \dot{\mathbf{u}}\right)=\nabla^{s} \dot{\mathbf{u}}(\mathbf{x}, t)-(\dot{\overline{\mathbf{u}}} \otimes \nabla \beta)^{s}
\end{aligned}
$$

Incorporating this modified strain/strain rate produces strains/strain rates (and hence stresses and impedances) which vary smoothly within the intermediate layer and across the layer boundaries.

\section{COMPARSION WITH CARES/SASSI}

For comparison with the current state-of-the-art, the soil was represented by a 3D extension of the simple nonlinear hysteretic Ramberg-Osgood material model, first developed in the work of Ramberg and Osgood (1943). The Ramberg-Osgood model requires the determination of four parameters to fit the behavior of each of the 9 soil layers, using an algorithm (RAMBO) developed earlier at LLNL, detailed in the work of Ueng and Chen (1992). Details of the model implementation are available in the NIKE3D manual, detailed in to Puso, M.A. (2014). Soil parameters were based on an existing site response analysis for 9 soil layers extracted from a deep soil location at the DOE Savannah River Site, detailed in Wyatt and Harris (2004). A description of the soil layers is 


\begin{tabular}{|c|l|c|c|c|c|}
\hline Layer & \multicolumn{1}{|c|}{$\begin{array}{c}\text { Depth at } \\
\text { the top of } \\
\text { the layer } \\
\text { (ft) }\end{array}$} & $\begin{array}{c}\text { Unit Weight } \\
\mathbf{( 1 0 0 0} \\
\text { pounds / } \\
\text { cubic foot) }\end{array}$ & $\begin{array}{c}\text { Effective } \\
\text { overburden } \\
(\mathbf{1 0 0 0} \text { pounds / } \\
\text { square foot) }\end{array}$ & $\begin{array}{c}\text { Initial Shear } \\
\text { Wave } \\
\text { Velocity } \\
\text { (feet/second) }\end{array}$ \\
\hline 1 & Upland & 0 & 0.125 & 1.872 & 1580 \\
\hline 2 & Tobacco Road & 30 & 0.128 & 6.558 & 1240 \\
\hline 3 & Dry Branch & 74 & 0.125 & 12.429 & 1200 \\
\hline 4 & Santee & 123 & 0.123 & 19.607 & 1564 \\
\hline 5 & Warley Hill & 190 & 0.132 & 24.716 & 2153 \\
\hline 6 & Congaree & 205 & 0.132 & 28.805 & 1720 \\
\hline 7 & Four Mile & 252 & 0.126 & 33.545 & 1415 \\
\hline 8 & Snapp & 278 & 0.132 & 36.83 & 1675 \\
\hline 9 & Sawdust Landing & 303 & 0.131 & 42.864 & 2015 \\
\hline 10 & Hard Rock & 370 & 0.15 & N/A & 11,000 \\
\hline
\end{tabular}

Figure 5 - Soil Profile

The soil properties as a function of strain, as well as the fits of the Ramberg-Osgood model versus the EPRI data are presented in terms of soil degradation and damping curves as Figure 6 thruFigure $\mathbf{1 0 .}$ Generally speaking the match is good. The worst match occurs for damping at the low values of strain. In particular, the Ramberg-Osgood model cannot produce damping at strain levels at or near zero. To compensate for this, a small amount of Rayleigh (viscous), damping (1.5\% of critical at 1 and $30 \mathrm{~Hz}) \mathrm{has}$ been introduced, in order to provide a good match to the response predicted by CARES. The need to introduce Rayleigh damping in the model is one of the greatest differences between a CARES and a DIABLO analysis, as Rayleigh damping is velocity-dependent whereas CARES uses exclusively hysteretic (non-velocity-dependent) damping.
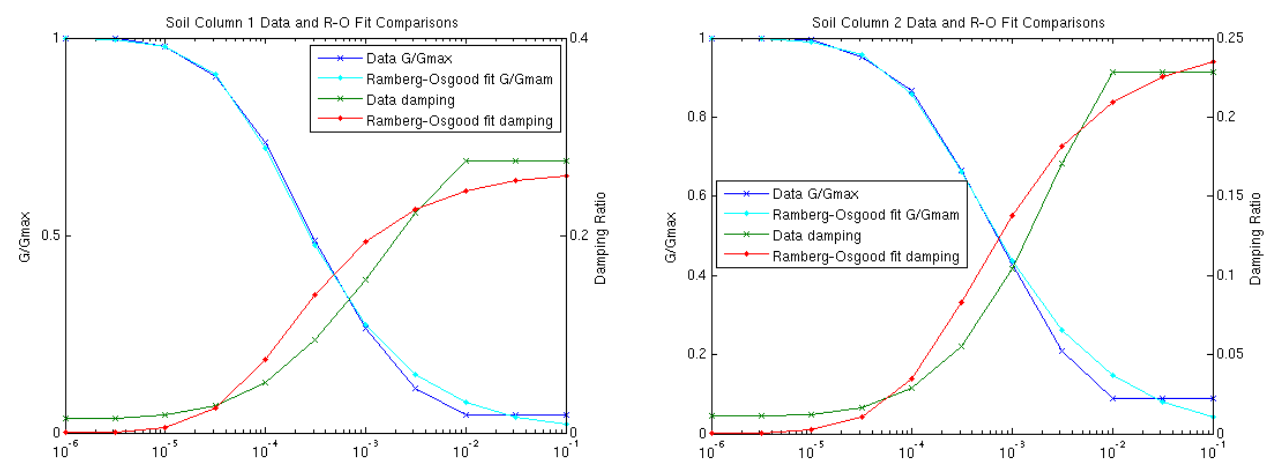

Figure 6 -Ramberg-Osgood fit versus data, soil columns 1 and 2. 

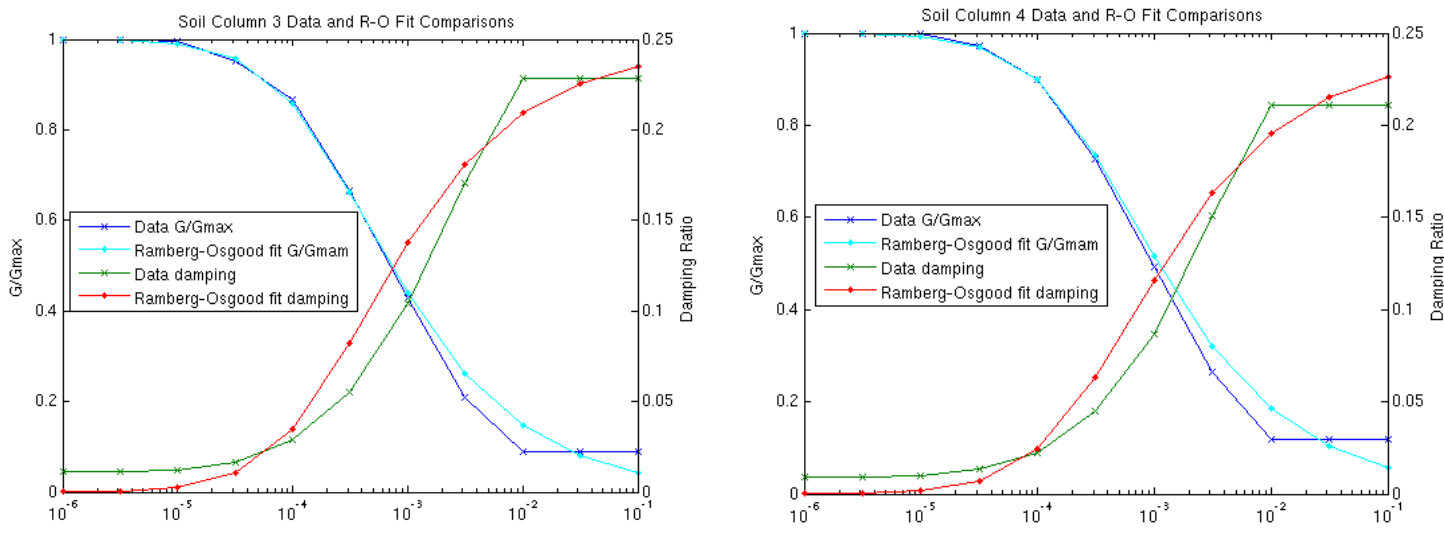

Figure 7 - Ramberg-Osgood fits versus data, soil columns 3 and 4.
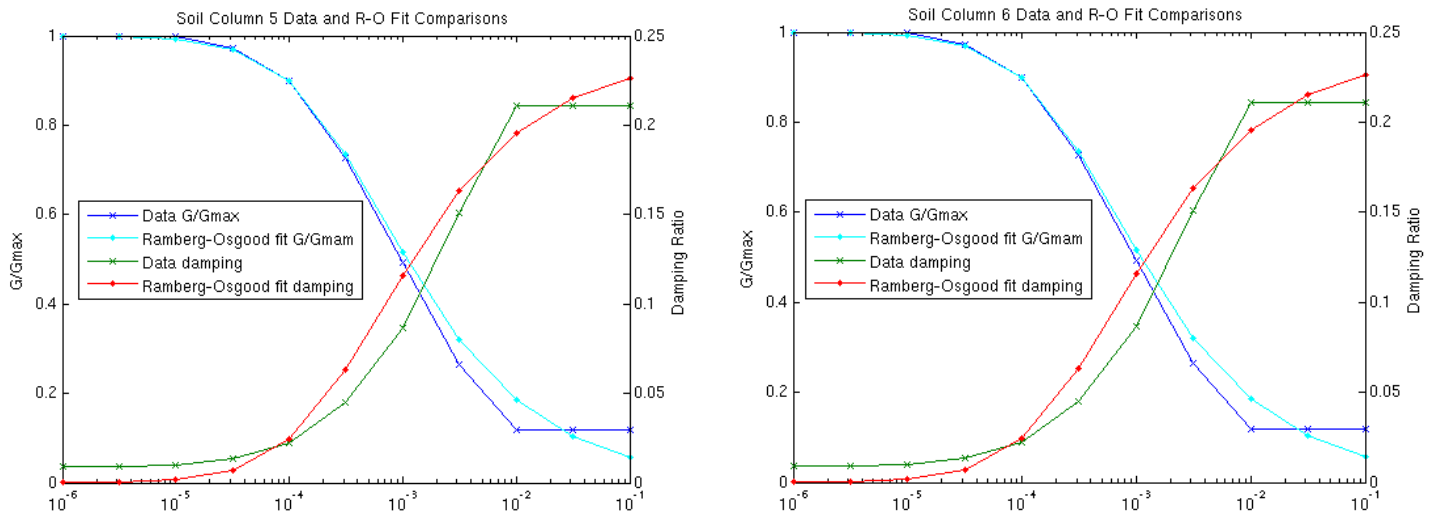

Figure 8 - Ramberg-Osgood fits versus data, soil columns 5 and 6.
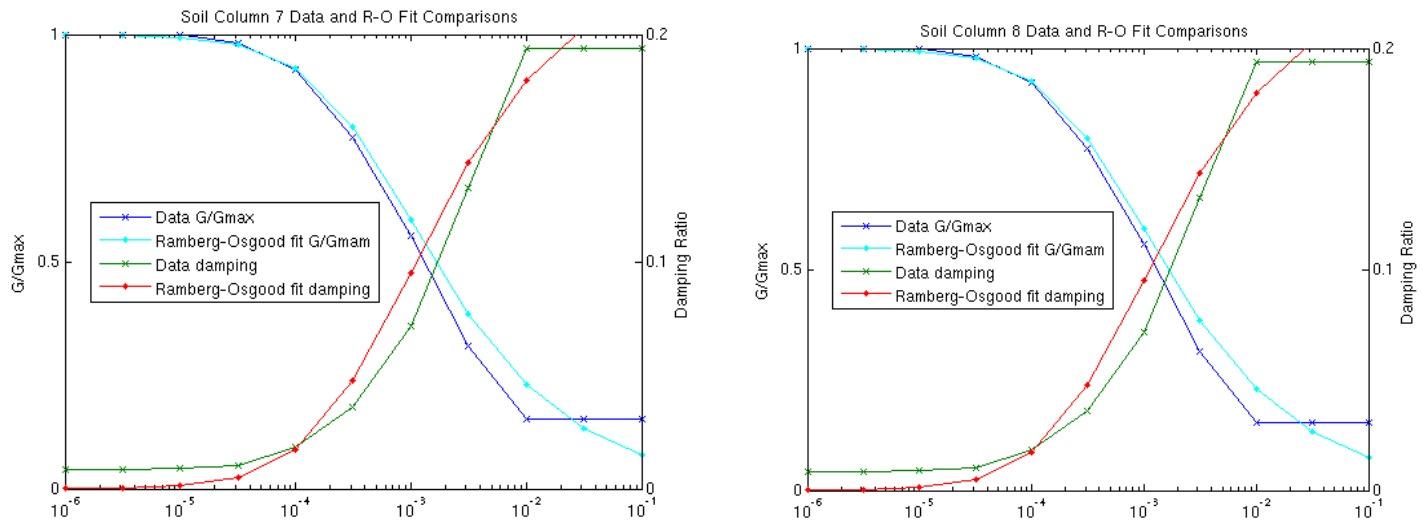

Figure 9 - Ramberg-Osgood fits versus data, Soil Columns 7 and 8. 


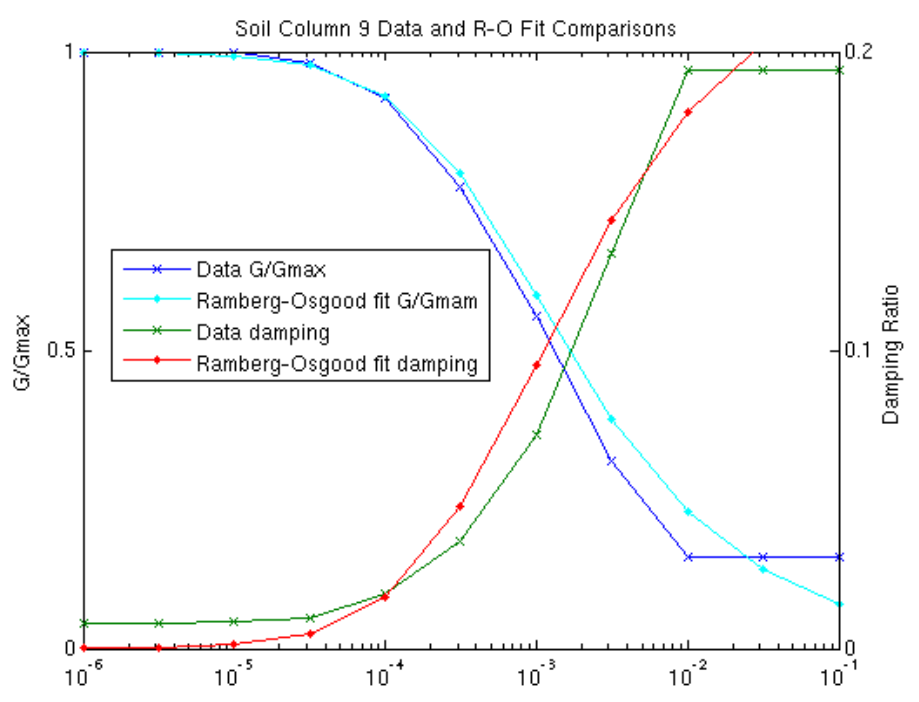

Figure 10 - Ramberg-Osgood fits versus data, Soil Column 9

The modulus degradation and damping parameters were utilized by Professor Carl Costantino within the 1-D Soil Column simulator CARES, documented in Costantino, Miller and Xu (1995), and used to extract equivalent-linear soil properties and predicted motions for notional $0.2 \mathrm{~g}, 0.5 \mathrm{~g}$, and $0.9 \mathrm{~g}$ earthquakes. In contrast to the equivalent-linear approach, the parameters for the Ramberg-Osgood model were only fit once, since they depend only on the soil data and not on the particular earthquake. Typical comparisons of 5\% damped response spectra (5\% damped harmonic oscillator subjected to the acceleration time history, max acceleration versus oscillator natural frequency) are provided as Figure 11 thru Figure 14, where the left hand figures represents the response to a $0.2 \mathrm{~g}$ earthquake at various distances from the top of the soil column, and the right hand figures represent the response at the same location to a $0.9 \mathrm{~g}$ earthquake.

In general, the match is pretty good (though of course that is a matter of opinion). Since the RambergOsgood model is nonlinear, with variable damping and modulus as a function of strain, the match is not expected to be exact. One notes that the general behavior is comparable, and neither CARES nor Diablo results exhibiting markedly different magnitudes or frequency response. Again, because of the nonlinear nature Diablo some differences are expected. As explained previously, because of the lack of damping provided by the Ramberg-Osgood model at low levels of strain, it was necessary to add some viscous damping. An exact match between the equivalent-linear frequency-domain model and a time-domain solution would only be expected for a time domain model which incorporates both constant elastic moduli and a large number of linear Maxwell elements in parallel, in order to approximate a linear material with constant hysteretic damping.

It should be noted that the quality of this match (whether judged good or not) is independent of the domain reduction method discussed in the majority of the work. The quality of the match is largely due to how well the nonlinear material model matches the constant damping solution. It is not expected to match exactly, and it is in some sense remarkable that a very simple nonlinear model is able to provide (in the author's judgement) a reasonably good representation of the equivalent linear model without any adjustment of parameters for different earthquake levels. One might even argue that the RambergOsgood results from Diablo are "more accurate", however that pre-supposes that the Ramberg-Osgood model is better than the equivalent-linear approach in all respects, which requires direct comparison to experimental data. 
If one inspects Figure 11, at the $0.2 \mathrm{~g}$ level there is a shift in the peaks between Diablo and CARES, with the Diablo peak at $0.7 \mathrm{~Hz}$ corresponding to the CARES peak at $1 \mathrm{~Hz}$, but the magnitudes of the peaks are roughly the same. At the $0.9 \mathrm{~g}$ level, the peak in CARES at a frequency of about $2.5 \mathrm{~Hz}$ is somewhat reduced, whereas the somewhat less prominent peak at roughly $10 \mathrm{~Hz}$ is larger in DIABLO than in CARES. At the 0.2g level the CARES and Diablo results converge about approximately $50 \mathrm{~Hz}$, whereas Diablo has greater response consistently above approximately $7 \mathrm{~Hz}$ for the $0.9 \mathrm{~g}$ level.
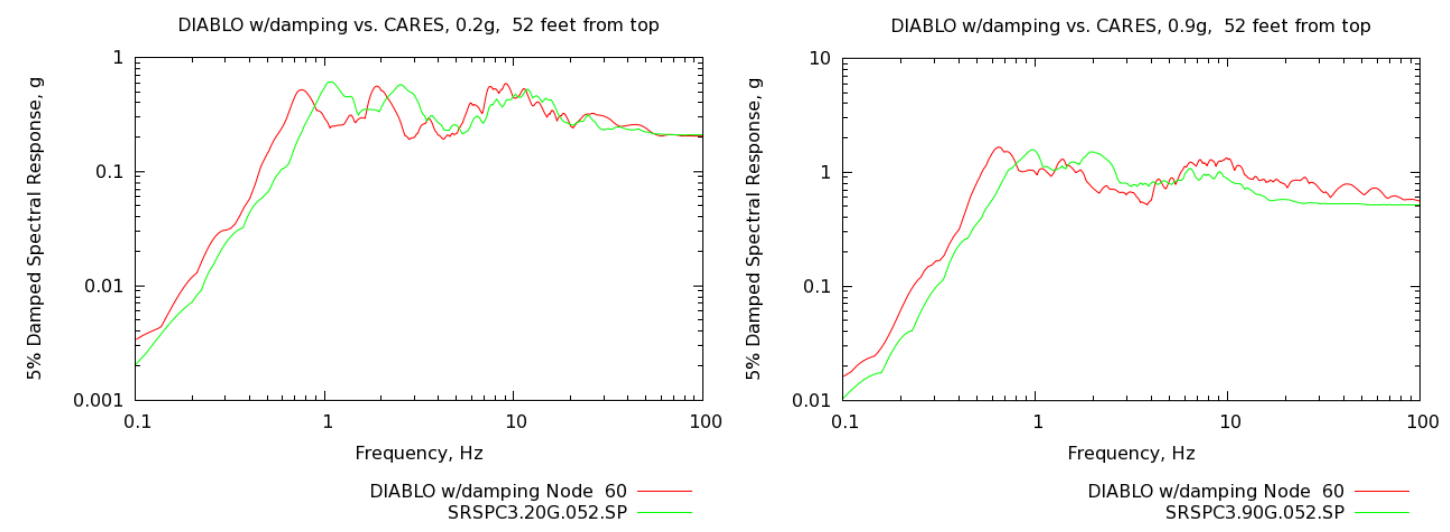

Figure 11 - DIABLO versus CARES for soil column position 52 feet from the top for $0.2 \mathrm{~g}$ and $0.9 \mathrm{~g}$ earthquake levels, $5 \%$ damped acceleration response spectra.

Examining now Figure 12, at $0.2 \mathrm{~g}$ again the first peak at approximately $1 \mathrm{~Hz}$ in CARES has a corresponding Diablo peak at about $0.7 \mathrm{~Hz}$, but the two peaks have approximately the same magnitude. In contrast to the results at 52 feet from the top, there is a large Diablo peak at $3.5 \mathrm{~Hz}$, which corresponds to a CARES peak at about $5 \mathrm{~Hz}$, but at a much lower level. The results at frequencies above $30 \mathrm{~Hz}$ converge to one another. The results at the $0.9 \mathrm{~g}$ show similar behavior, except now the first Diablo peak at $0.7 \mathrm{~Hz}$ has a higher magnitude than the corresponding CARES peak at around $1 \mathrm{~Hz}$. The peak response for Diablo at about $3.5 \mathrm{~Hz}$ has a higher magnitude than the corresponding CARES peak, which in this case is at about $4 \mathrm{~Hz}$. Again, while the results at $0.2 \mathrm{~g}$ converge for frequencies above about $11 \mathrm{~Hz}$, Diablo has larger spectral response than CARES for all frequencies above approximately $10 \mathrm{~Hz}$ at the $0.9 \mathrm{~g}$ level, including a relatively prominent peak at around $10.5 \mathrm{~Hz}$.
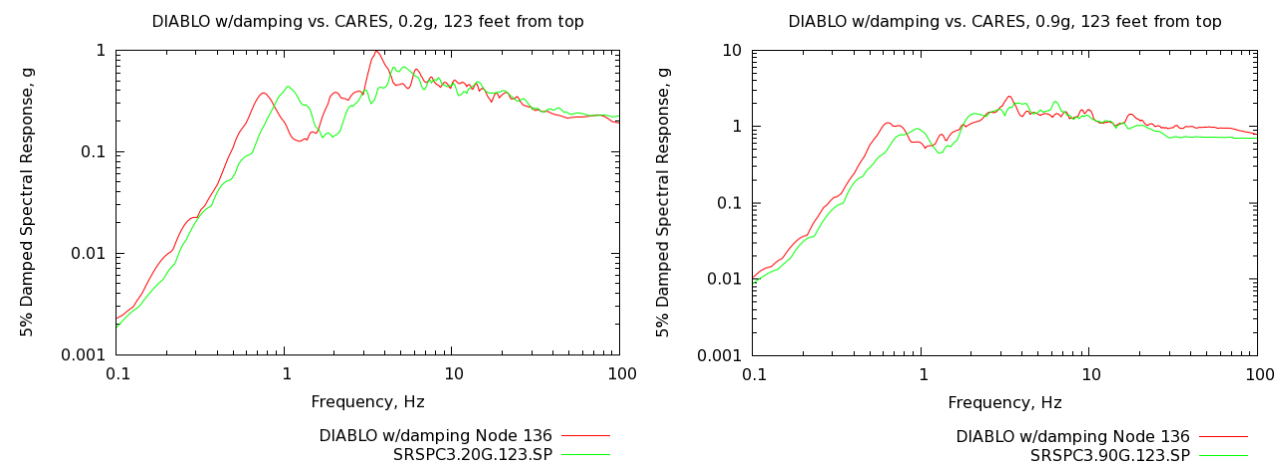

Figure 12 - DIABLO versus CARES for soil column position 123 feet from the top for $0.2 \mathrm{~g}$ and $0.9 \mathrm{~g}$ earthquake levels, $5 \%$ damped acceleration response spectra.

Examining Figure 13, at $0.2 \mathrm{~g}$ again the first peak at approximately $1 \mathrm{~Hz}$ in CARES has a corresponding Diablo peak at about $0.7 \mathrm{~Hz}$, but the two peaks have approximately the same magnitude. There is again an intermediate peak in Diablo at $1.9 \mathrm{~Hz}$, which corresponds to a rather flat CARES peak 
at $1.5 \mathrm{~Hz}$. There is another Diablo peak at $3.5 \mathrm{~Hz}$ which corresponds to a CARES peak at roughly $5.5 \mathrm{~Hz}$. The results at frequencies above $30 \mathrm{~Hz}$ converge to one another, but not as well as in Figures 11 and 12 . The results at the $0.9 \mathrm{~g}$ show similar behavior, except now the first Diablo peak at $0.7 \mathrm{~Hz}$ has a higher magnitude than the corresponding CARES peak at around $1 \mathrm{~Hz}$. The intermediate peak for Diabloo at 1.5 $\mathrm{Hz}$ now has a lower magnitude than the CARES peak at about $2.5 \mathrm{~Hz}$. In this instance the Diablo and CARES results tend to converge for frequencies above about $30 \mathrm{~Hz}$, though CARES results are greater than Diablo results at $100 \mathrm{~Hz}$.
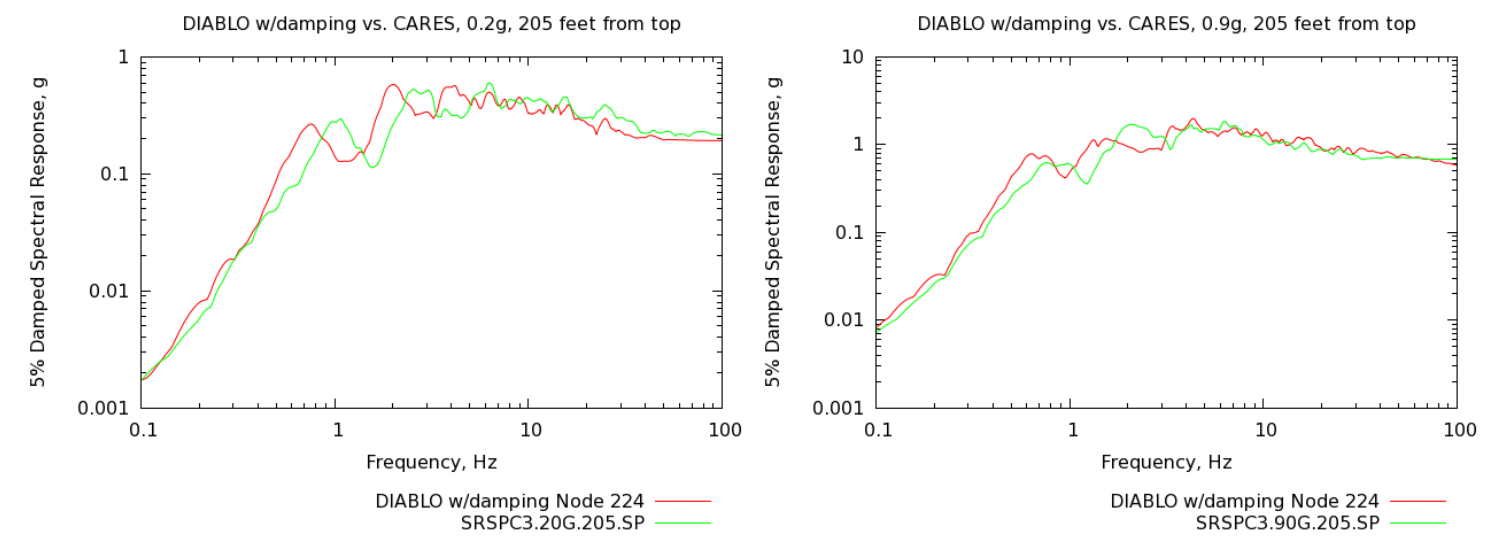

Figure 13 - DIABLO versus CARES for soil column position 205 feet from the top for $0.2 \mathrm{~g}$ and $0.9 \mathrm{~g}$ earthquake levels, $5 \%$ damped acceleration response spectra.

Examining Figure 14, at $0.2 \mathrm{~g}$ again the first peak at approximately $1 \mathrm{~Hz}$ in CARES has a corresponding Diablo peak at about $0.7 \mathrm{~Hz}$, but the two peaks have approximately the same magnitude, with the Diablo results slightly lower. In this case there is a prominent intermediate peak which for CARES is at about $2.5 \mathrm{~Hz}$ and Diablo at about $1.9 \mathrm{~Hz}$, again with similar magnitudes, though the shape of the peak differs somewhat between CARES and Diablo. Again there is a large Diablo peak at $3.5 \mathrm{~Hz}$, which corresponds to a CARES peak at about $5 \mathrm{~Hz}$, but at a much lower level. The results at frequencies above $30 \mathrm{~Hz}$ converge to one another. The results at the $0.9 \mathrm{~g}$ are a bit better. The peak response for Diablo at about $3.5 \mathrm{~Hz}$ has a slightly higher magnitude than the corresponding CARES peak, which in this case is at about $5 \mathrm{~Hz}$. The results above about $10 \mathrm{~Hz}$ converge to each other.
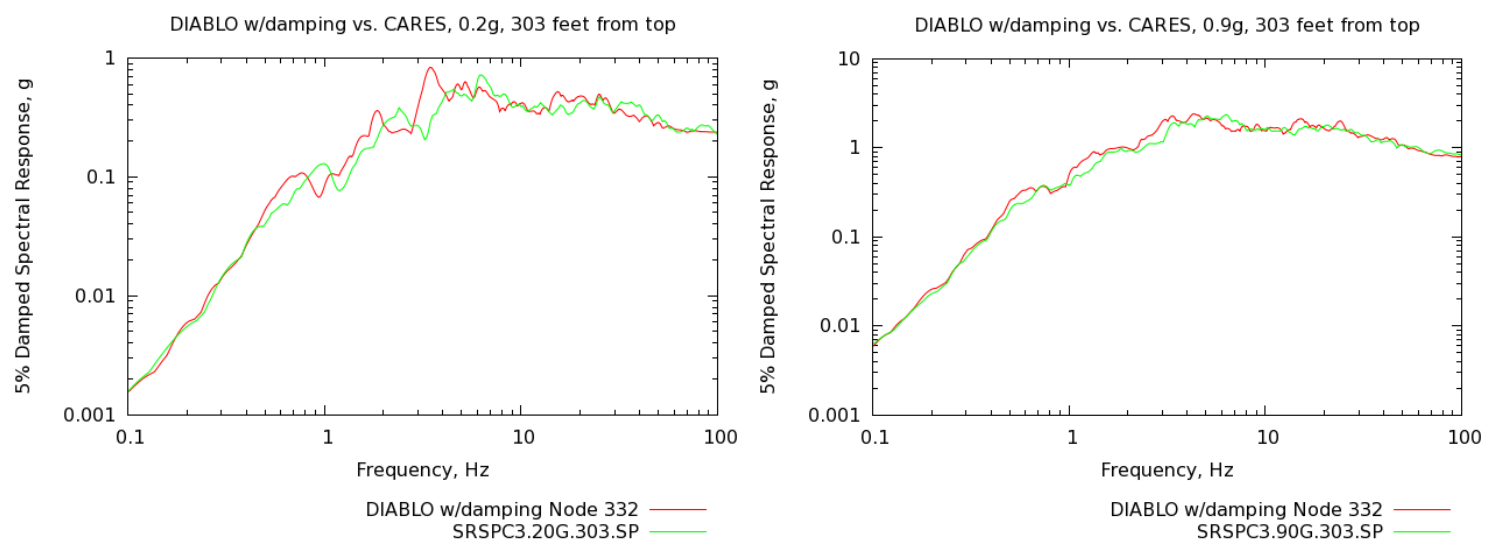

Figure 14 - DIABLO versus CARES for soil column position 303 feet from the top for $0.2 \mathrm{~g}$ and $0.9 \mathrm{~g}$ earthquake levels, $5 \%$ damped acceleration response spectra. 
For a more comprehensive comparison, a notional Small Modular Reactor was conceived and modeled (Figure 20, left and center), using typical 4-node shell elements, consisting of a basemat, 3 floors, and a roof. A cylindrical reactor vessel centrally located was supported by a cylindrical ring $1 / 3$ of the way from the base of the vessel, and restrained by lateral beams at the level of the second floor. The cylindrical ring rested on a central cylindrical pier, which extended to the base of the third floor and supported these three floors. The roof was supported by columns emanating from the top of the central cylindrical pier. Plans for the small modular reactor are included in Figure 15 Figure 17.

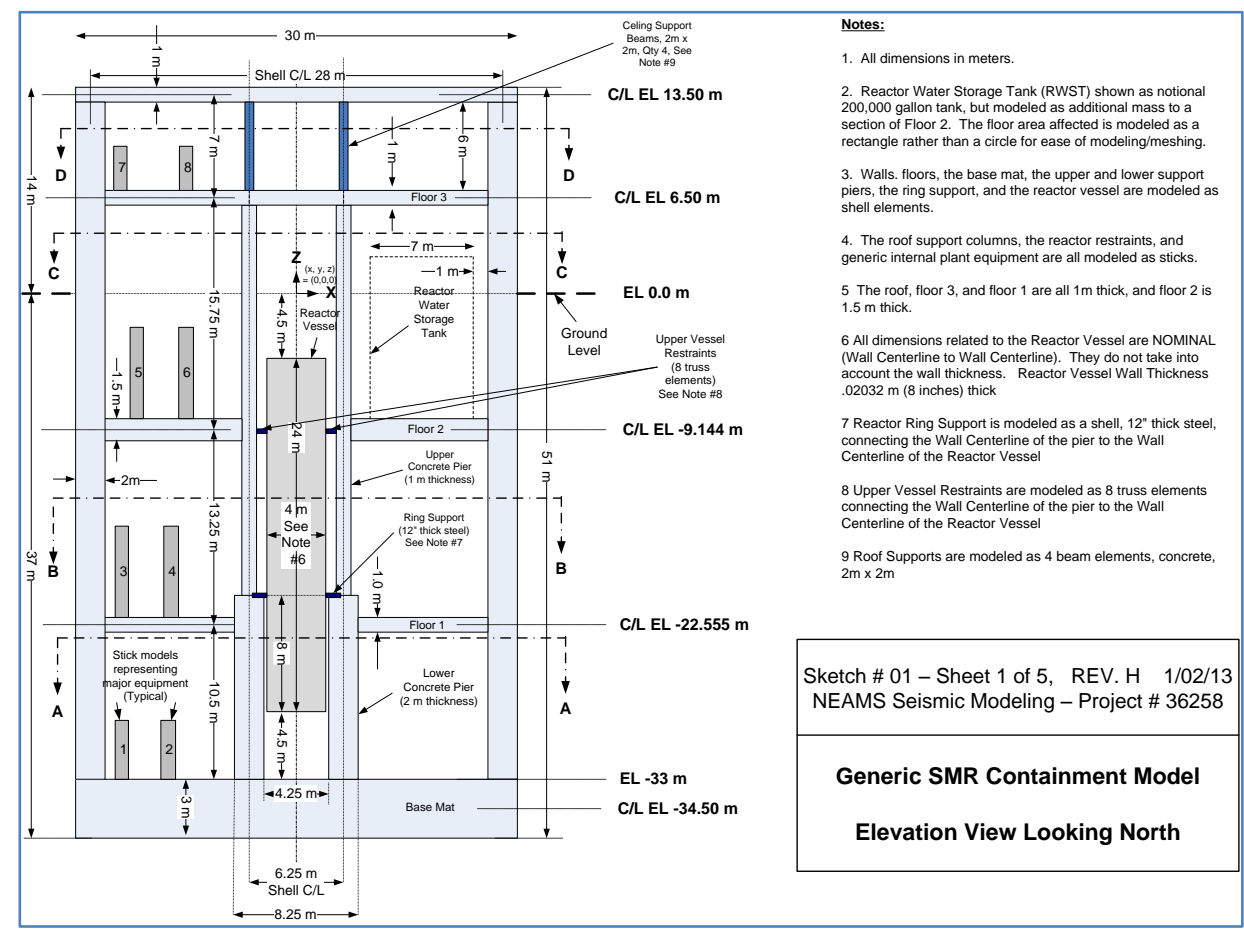

Figure 15 - Notional Small Modular Reactor, elevation view 


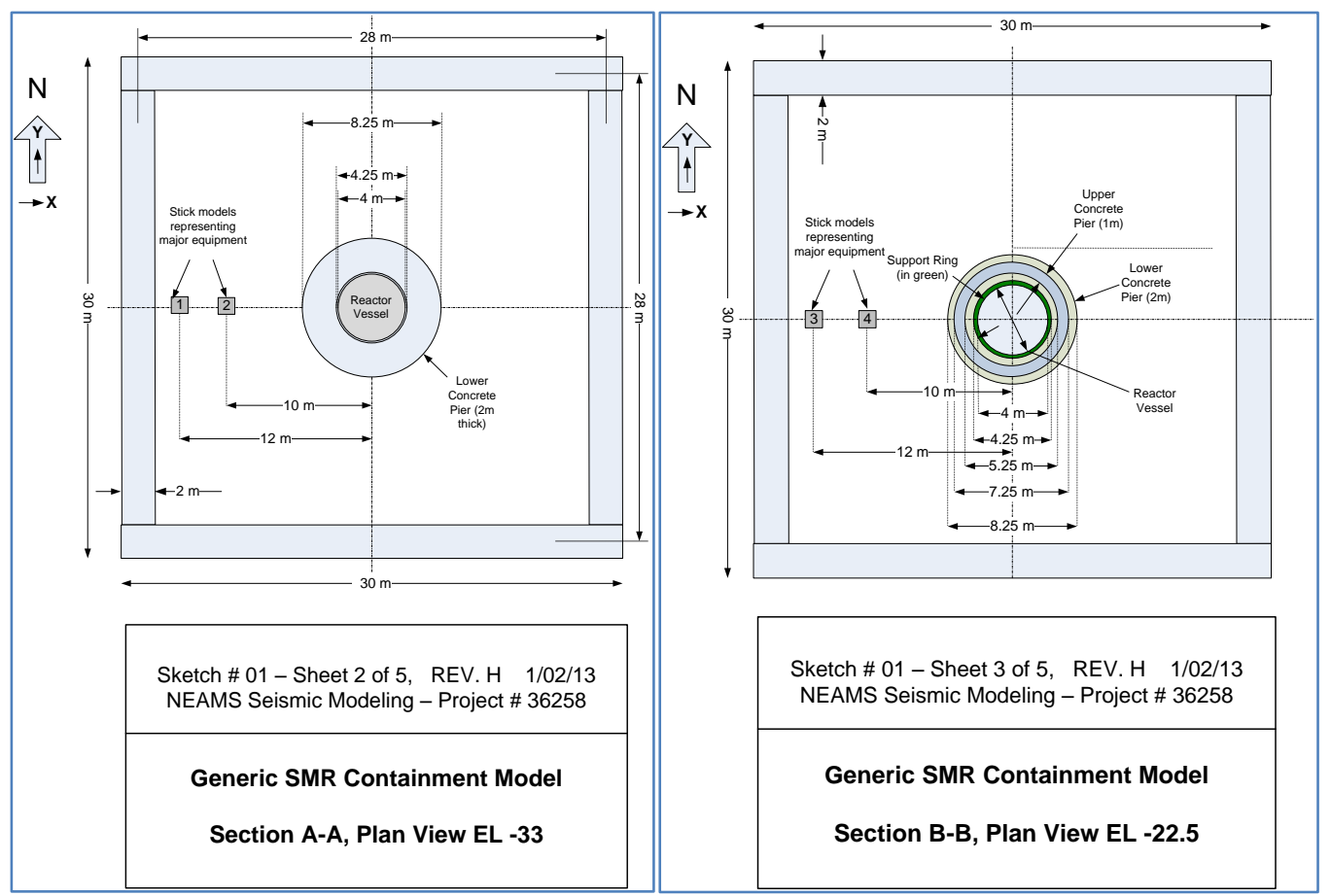

Figure 16 - Notional Small Modular Reactor, floor plans part 1/2

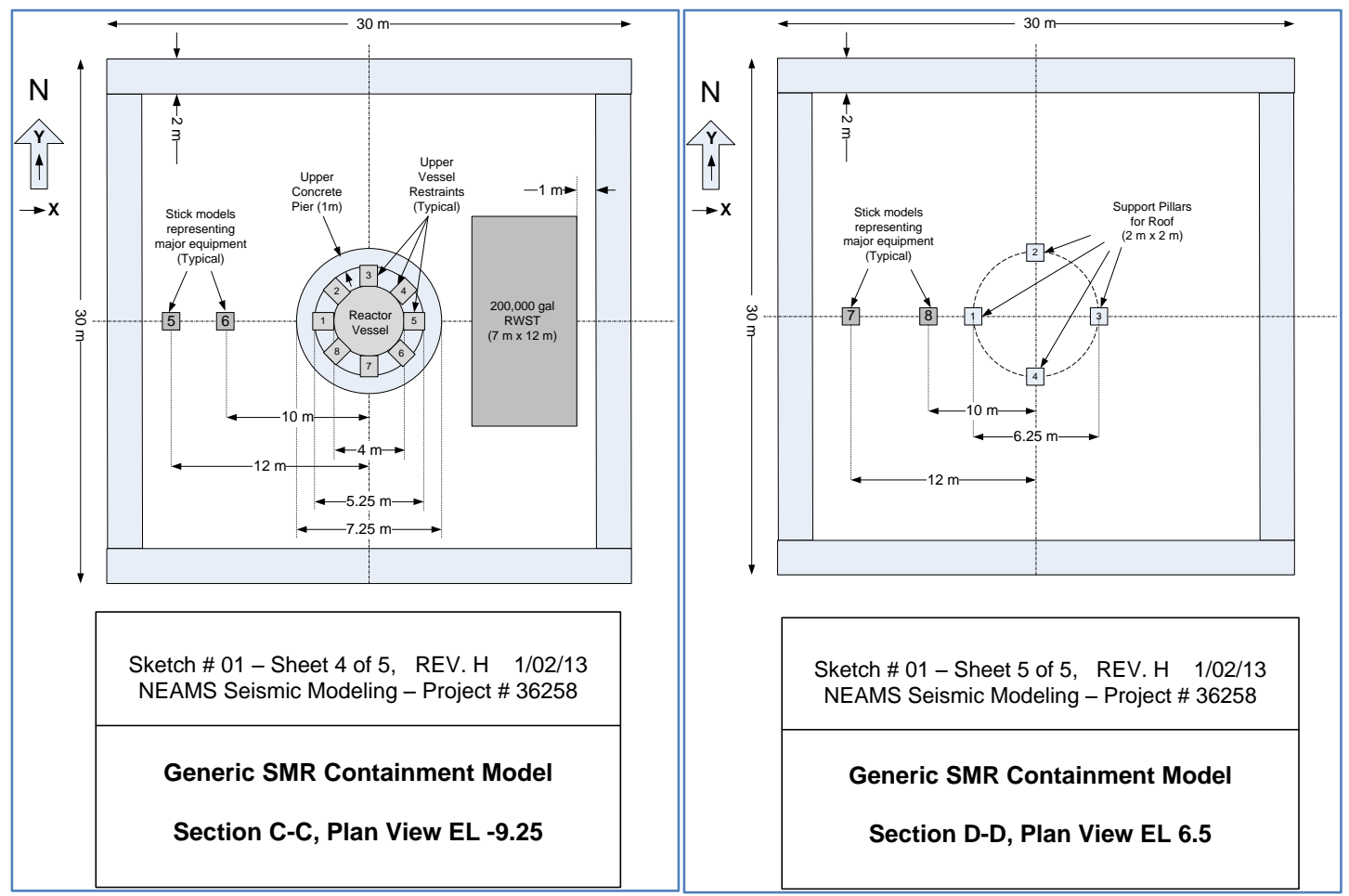

Figure 17 - Notional Small Modular Reactor, Floor plans part 2/2

A number of stick models (using 2-node beam elements) were included to model the effects of equipment, as well as a section of the second floor with a greatly increased floor weight, representing the presence of a water tank. Material and structural properties and associated notes are provided as Figure 18. 

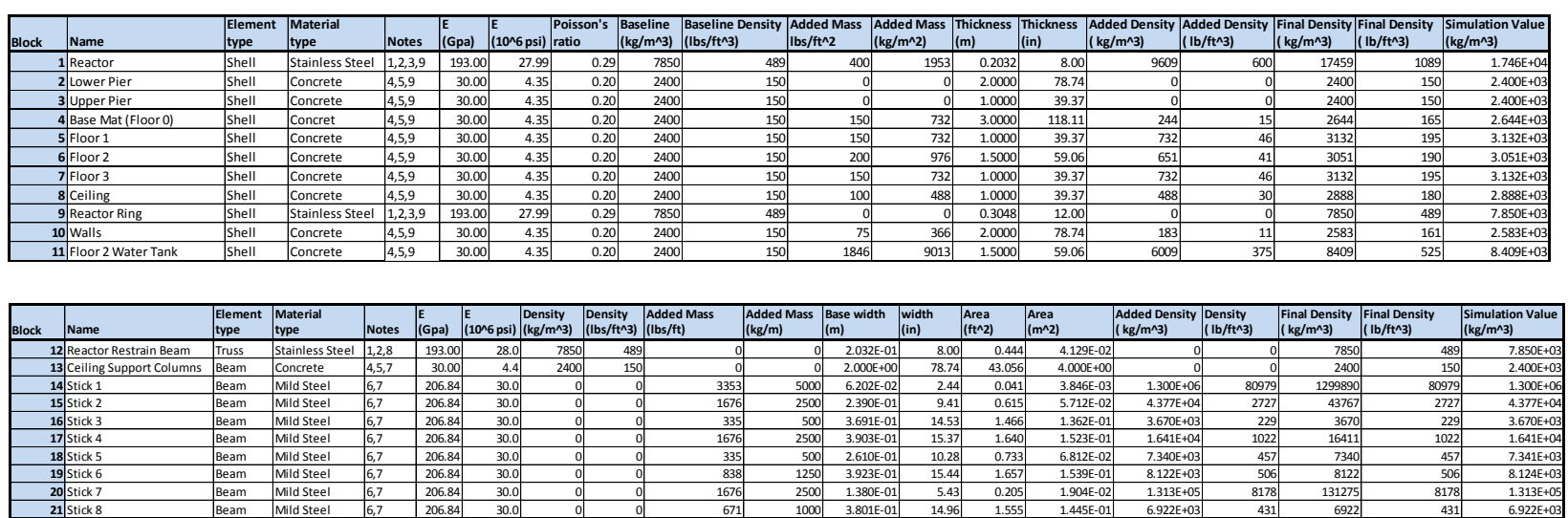

\begin{tabular}{|c|c|c|c|c|c|c|c|c|}
\hline Stick Number & \begin{tabular}{c|} 
Target \\
Frequency, $\mathrm{f}$
\end{tabular} & Length (m) & $\begin{array}{l}\text { Distributed Weight } \\
\text { (kg/meter) }\end{array}$ & $\begin{array}{l}\text { Moment of Inertia } \\
\left(\text { meter }^{4}\right) \text {, assuming } \\
E=30 \times 10^{6} \mathrm{psi}\end{array}$ & $\begin{array}{l}\text { No. of Nodes including } \\
\text { the top and the Bottom }\end{array}$ & $\begin{array}{c}\text { Equivalent base } \\
\text { width ( } \mathrm{m} \text { ) assuming } \\
\text { square }\end{array}$ & $\begin{array}{c}\text { Equivalent Area }\left(\mathrm{m}^{\wedge} \mathbf{2}\right) \text { assuming } \\
\text { square }\end{array}$ & $\begin{array}{c}\text { Equivalent Mass } \\
\text { Density } \\
\left(\mathrm{kg} / \mathrm{m}^{\wedge} 3\right)\end{array}$ \\
\hline 1 & 1 & 2 & 5000 & $1.23 \mathrm{E}-06$ & 3 & $6.202 \mathrm{E}-02$ & 3.85E-03 & $1.300 E+06$ \\
\hline 2 & 21 & 2 & 2500 & $2.72 \mathrm{E}-04$ & 3 & $2.390 \mathrm{E}-01$ & $5.71 \mathrm{E}-02$ & 4.377E+04 \\
\hline 3 & 7 & 8 & 500 & $1.55 \mathrm{E}-03$ & 5 & $3.691 \mathrm{E}-01$ & $1.36 \mathrm{E}-01$ & $3.670 \mathrm{E}+03$ \\
\hline 4 & 14 & 4 & 2500 & $1.93 \mathrm{E}-03$ & 3 & 3.903E-01 & $1.52 \mathrm{E}-01$ & $1.641 \mathrm{E}+04$ \\
\hline 5 & 14 & 4 & 500 & $3.87 \mathrm{E}-04$ & 3 & $2.610 \mathrm{E}-01$ & $6.81 \mathrm{E}-02$ & $7.341 E+03$ \\
\hline 6 & 5 & 8 & 1250 & $1.97 \mathrm{E}-03$ & 5 & $3.923 \mathrm{E}-01$ & $1.54 \mathrm{E}-01$ & $8.124 E+03$ \\
\hline 7 & 7 & 2 & 2500 & $3.02 \mathrm{E}-05$ & 3 & $1.380 \mathrm{E}-01$ & $1.90 \mathrm{E}-02$ & 1.313E+05 \\
\hline 8 & 21 & 4 & 1000 & $1.74 \mathrm{E}-03$ & 3 & $3.801 \mathrm{E}-01$ & $1.44 \mathrm{E}-01$ & $6.922 \mathrm{E}+03$ \\
\hline
\end{tabular}

Figure 18 - Material and Sectional Properties

Initial eigenvalue analysis runs were made to validate the model and the choice of parameters. For the purposes of a SASSI-DIABLO comparison, only modes with frequencies less than $30 \mathrm{~Hz}$ were considered. These runs were made to ascertain the quality of the structural representation, before transmitting the CUBIT finite element model of the Reactor Building to BNL for SASSI runs. A final eigenvalue analysis was performed with DIABLO, the results of which were confirmed by comparing with those from the LLNL code NIKE3D. Seventy-two (72) modes were found below $30 \mathrm{~Hz}$, thirty of which are listed below as Figure 19.

\begin{tabular}{|l|l|l|}
\hline Mode\# & Frequency & Description \\
\hline 1 & 0.981 & Stick \#1, mode 1, y \\
\hline 2 & 0.981 & Stick \#1, mode 1, $\mathrm{x}$ \\
\hline 3 & 4.56 & Structural mode \\
\hline 4 & 4.56 & Structural mode \\
\hline 5 & 4.95 & Stick \#6 \\
\hline 6 & 4.95 & Stick \#6 \\
\hline 7 & 6.18 & Stick \#1, mode 2 \\
\hline 8 & 6.19 & Stick \#1, mode 2 \\
\hline 9 & 6.84 & Stick \#7 \\
\hline 10 & 6.85 & Stick \#7 \\
\hline 11 & 6.88 & Stick \#3 \\
\hline 12 & 6.88 & Stick \#3 \\
\hline 13 & 8.85 & Structural Twist \\
\hline 14 & 12.4 & Structural Bend \\
\hline 15 & 12.5 & Sticks \#4 and 5 \\
\hline
\end{tabular}




\begin{tabular}{|l|l|l|}
\hline 16 & 12.8 & Structural Z-mode \\
\hline 17 & 13.3 & Stick \#4 \\
\hline 18 & 13.4 & Stick \#4 \\
\hline 19 & 13.8 & Stick \#5 \\
\hline 20 & 13.9 & Stick \#5 \\
\hline 21 & 15.9 & Reactor Vessel Bending \\
\hline 22 & 16.0 & Reactor Vessel Bending \\
\hline 23 & 16.7 & Structural Z mode \\
\hline 24 & 17.0 & Reactor Vessel Bending + Floor 2 \\
\hline 25 & 17.5 & Roof and Floor 3 Bending \\
\hline 26 & 17.6 & Roof and Floor 3 Bending \\
\hline 27 & 18.4 & Roof and Floor 3 Bending \\
\hline 28 & 18.4 & Roof and Floor 3 Bending \\
\hline 29 & 18.4 & General Floor and Vessel Bending \\
\hline 30 & 18.8 & General Floor and Vessel Bending \\
\hline
\end{tabular}

Figure 19 - First 30 Eigenvalues

The reactor model was embedded in a layered soil domain with layer properties and spacing as in the 1D soil column analysis (Figure 20, right) and the entire model (soil and reactor) subjected to the notional $0.2 \mathrm{~g}, 0.5 \mathrm{~g}$, and $0.9 \mathrm{~g}$ earthquake loads, represented as vertically propagating shear waves.
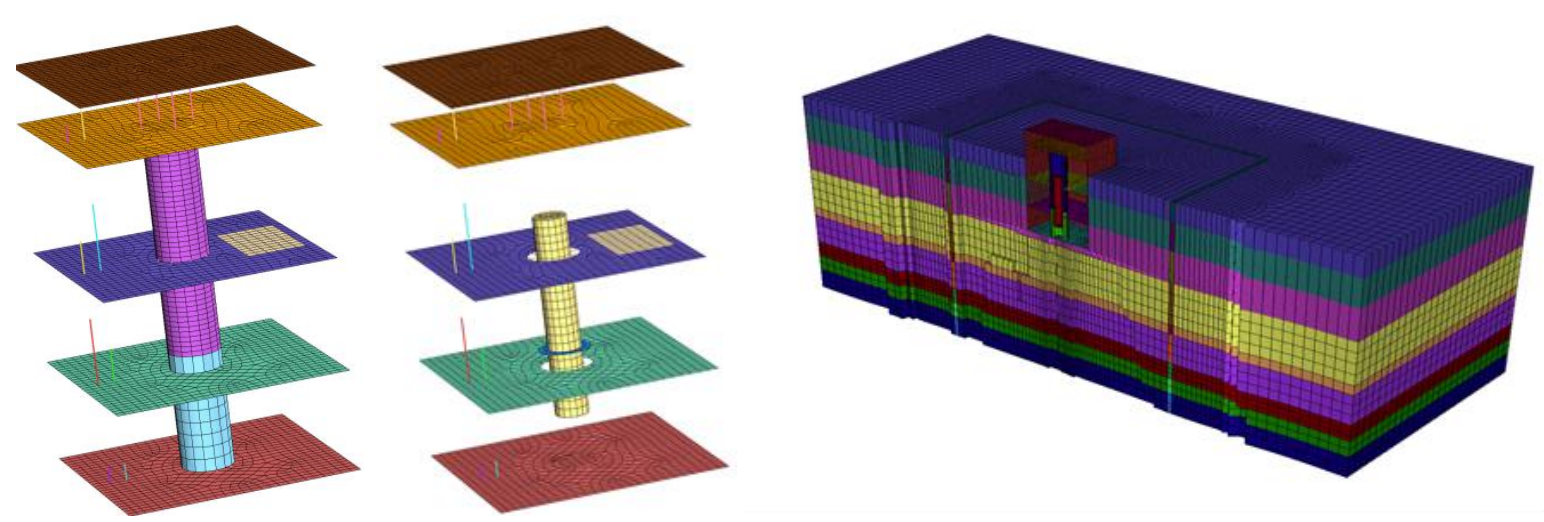

Figure 20 - Notional Small Modular Reactor, with outer walls removed (left), and with outer walls and piers removed (center), and embedded within layered soil (right)

The DIABLO analysis using the Ramberg-Osgood material model and the modified domain reduction method was compared to SASSI analysis performed by Brookhaven National Laboratory using the equivalent-linear material properties as determined by the aforementioned CARES analysis. The solution was compared at selected points in the reactor structure both in terms of maximum acceleration (Figure 21 thru Figure 24) and via 5\% damped response spectra (Figure 25 thru Figure 48).

Close examination of Figure 8 shows a good match of the peak accelerations versus SASSI. Typically peak response match is worst at the larger earthquake levels, for which differences in material response are likely to be accentuated. Generally speaking, DIABLO has lower peak acceleration than SASSI at these higher earthquake levels, but this trend does not hold in all cases. 


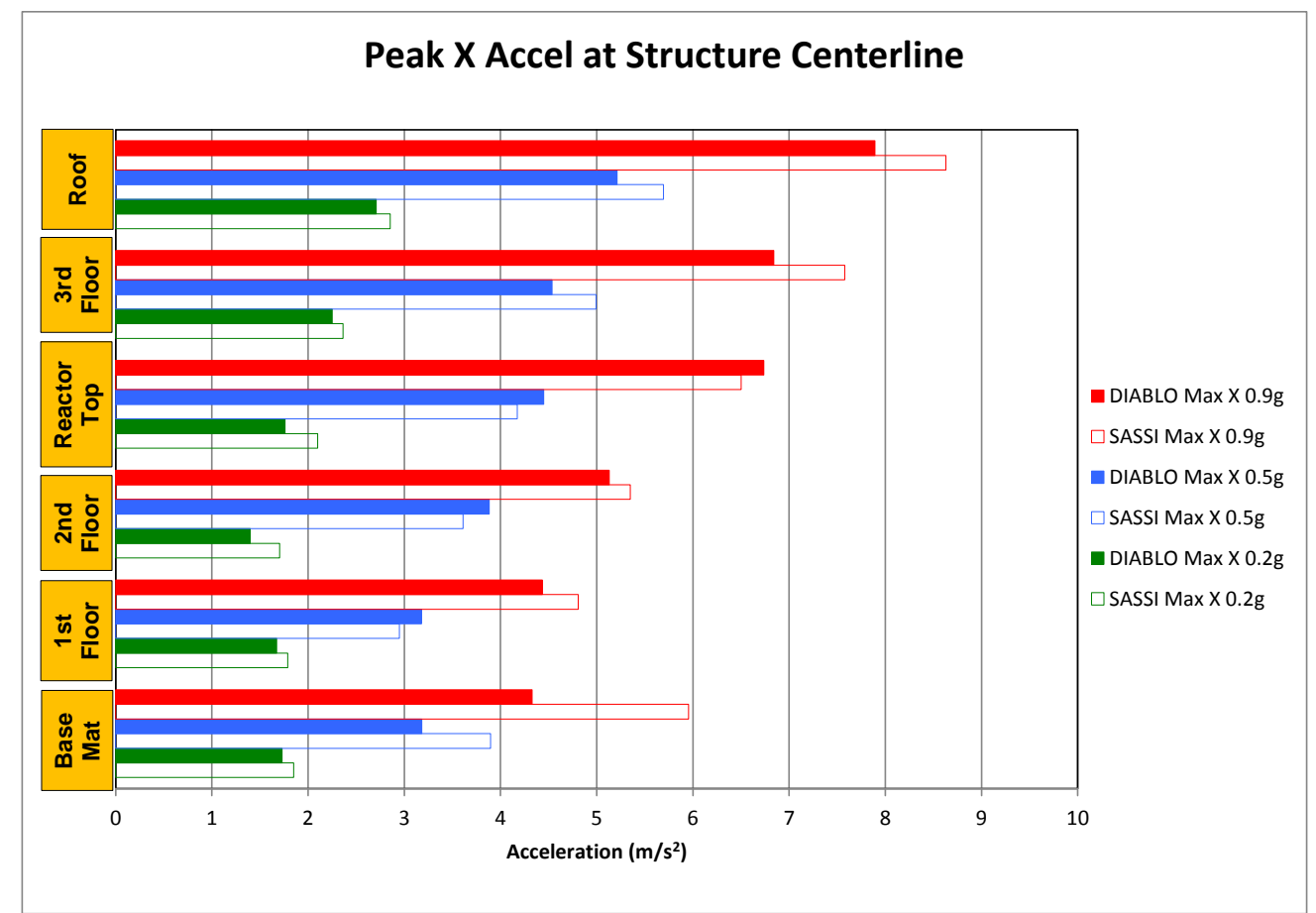

Figure 21 - Comparison of peak x-acceleration, SASSI (open bars) versus DIABLO (solid bars), at various locations along the structure centerline, for earthquake levels $0.2 \mathrm{~g}$ (green), $0.5 \mathrm{~g}$ (blue), and $0.9 \mathrm{~g}$ (red)

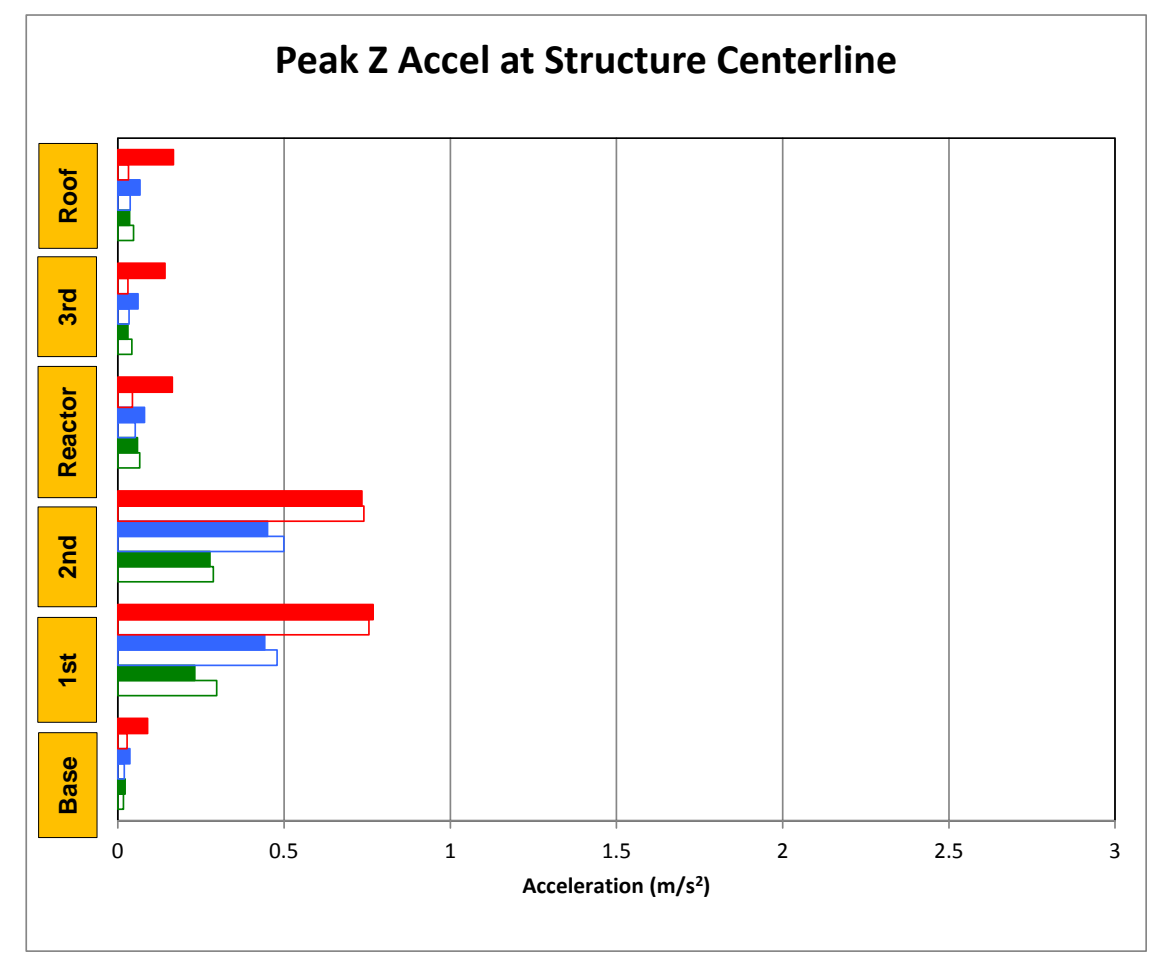

Figure 22 - Comparison of peak z-acceleration, SASSI (open bars) versus DIABLO (solid bars), at various locations along the structure centerline, for earthquake levels $0.2 \mathrm{~g}$ (green), $0.5 \mathrm{~g}$ (blue), and $0.9 \mathrm{~g}$ (red). Legend is the same as Figure 21. 


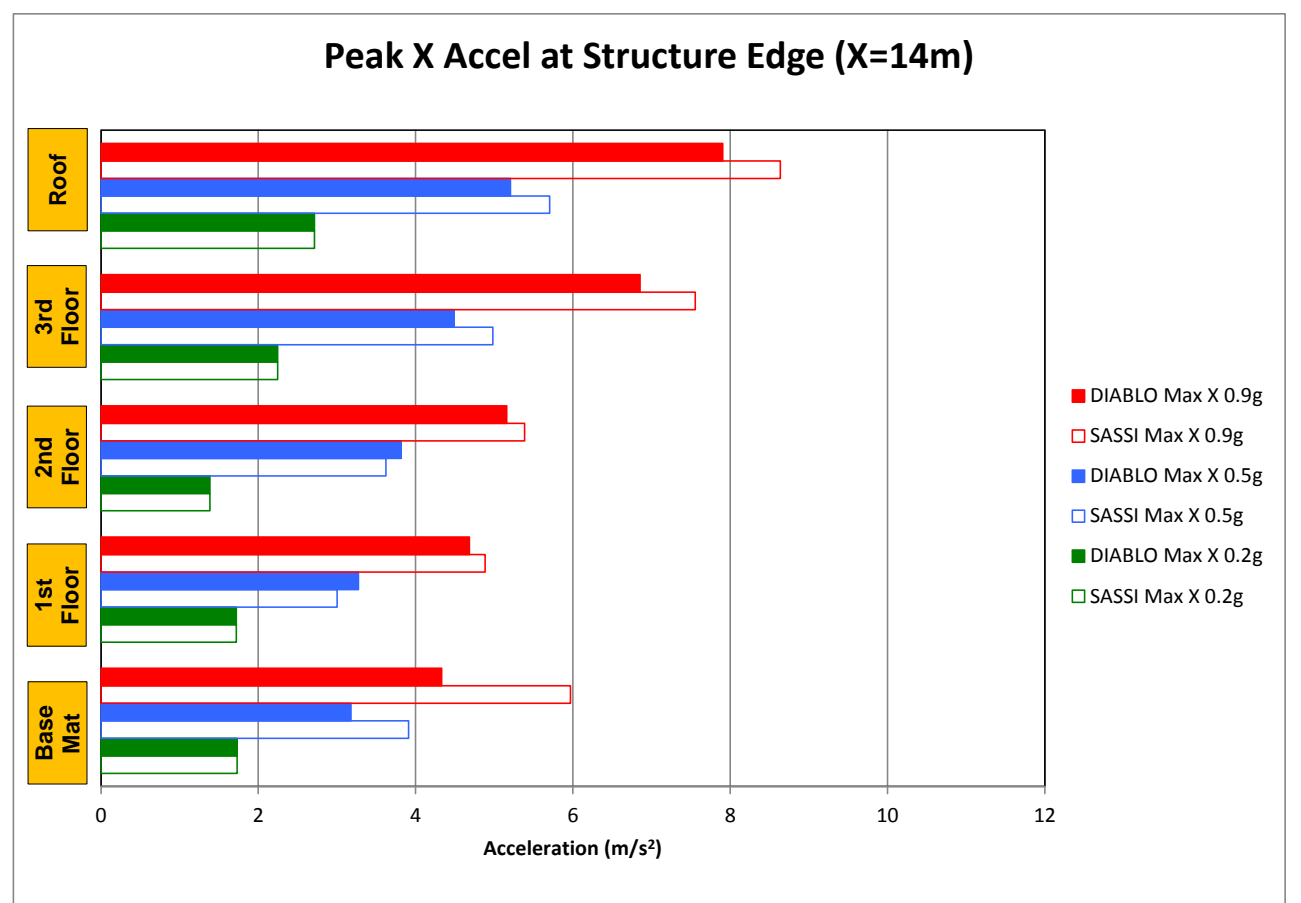

Figure 23 - Comparison of peak x-acceleration, SASSI (open bars) versus DIABLO (solid bars), at various locations along the structure $\mathrm{x}=14 \mathrm{~m}$ edge, for earthquake levels $0.2 \mathrm{~g}$ (green), $0.5 \mathrm{~g}$ (blue), and $0.9 \mathrm{~g}$ (red).

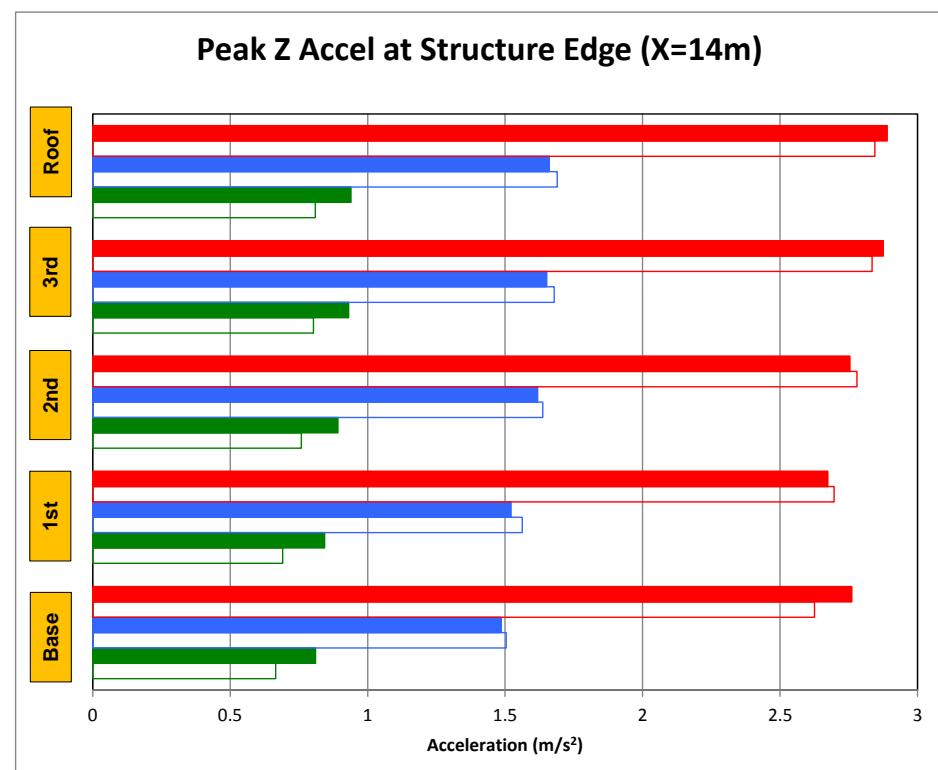

Figure 24 - Comparison of peak z-acceleration, SASSI (open bars) versus DIABLO (solid bars), at various locations along the structure $\mathrm{x}=14 \mathrm{~m}$ edge, for earthquake levels $0.2 \mathrm{~g}$ (green), $0.5 \mathrm{~g}$ (blue), and $0.9 \mathrm{~g}$ (red). Legend is the same as Figure 23

Examination of Figure 21 and Figure 23 indicate a good match across all frequencies and earthquake levels for X-direction acceleration levels. On the other hand, examination of Figure 22 finds that SASSI predicts a significantly lower response in comparison to DIABLO for Z direction response at certain positions along the structure centerline, whereas examination of Figure 24 finds again a good 
match. This behavior is most probably due to the reduced damping and higher modulus at low strain levels (in comparison to SASSI, which has fixed modulus and strain for each earthquake level) utilized in the Ramberg-Osgood model within DIABLO, supported by the observation that the Z-component match becomes progressively worse where the response is small (for example along the reactor centerline at the basemat or the roof), where SASSI would have significantly greater inherent damping in comparison with DIABLO, which at such low response levels is relying exclusively on Rayleigh damping. Examining Figure 21, Figure 23 and Figure 24, a general conclusion might be made that the best match occurs at the intermediate response levels, where the damping and modulus behavior of SASSI and Diablo have the closest match. At lower response levels, DIABLO tends to predict a greater response than SASSI, most probably because of the reduced damping exhibited by the Ramberg-Osgood model. At higher response levels, SASSI tends to predict slightly higher response than DIABLO, most probably because SASSI's modulus and damping values are fixed, whereas at high levels of strain DIABLO's Ramberg-Osgood model exhibits increased damping and reduced modulus.

More detailed response at various positions and earthquake inputs is provided by $5 \%$ damped acceleration response spectra in Figure 25 through Figure 48. Generally speaking, for intermediate and large values of response, the magnitudes and shape of the response spectra is very comparable, with an observed shift in frequency peaks between DIABLO and SASSI, especially at the $0.2 \mathrm{~g}$ level, for example Figure 25, Figure 31, Figure 37, and Figure 43 In contrast, where the response is low the match between DIABLO and SASSI is relatively poor, for example Figure 29, Figure 30, Figure 40, Figure 41 and Figure 42. Again, these differences are largely due to the difference between how SASSI and DIABLO handle damping at low response levels. Generally speaking these differences are magnified at higher earthquake levels, since DIABLO is dynamically adapting the damping to a low level in regtions and directions where the response is small whereas SASSI is using a uniformly large value of damping in this region.

From a top level perspective, it is not realistic to expect a perfect match between DIABLO and SASSI given that DIABLO utilizes dynamically varying modulus and damping, whereas for a particular anlalysis the damping and moduli are fixed. In addition, the Ramberg-Osgood model used within DIABLO cannot adequately capture damping at low response levels, and hence Rayleigh damping is used to achieve a closer match in this area of phase space. Given these caveats, it is remarkable how well the SASSI behavior is captured by DIABLO, noting that the match to EPRI data was only done once, without resorting to matching a vertically-propagating shear wave analysis for a particular earthquake, as in SASSI.

For future work, one might consider comparing various models which may more closely match the "constant modulus, constant hysteretic damping" behavior of SASSI. This may include plasticity-like models based on a frictional framework, or linear elastic materials augmented with a large system of Maxwell elements. However, another point of view would be that the Ramberg-Osgood model is a better representation of the physics than the equivalent-linear model used within SASSI, and future work should aim towards more physically-based models which have a consistent continuum mechanics representation in the time domain, such as pressure-dependent nonlinear soil models. 


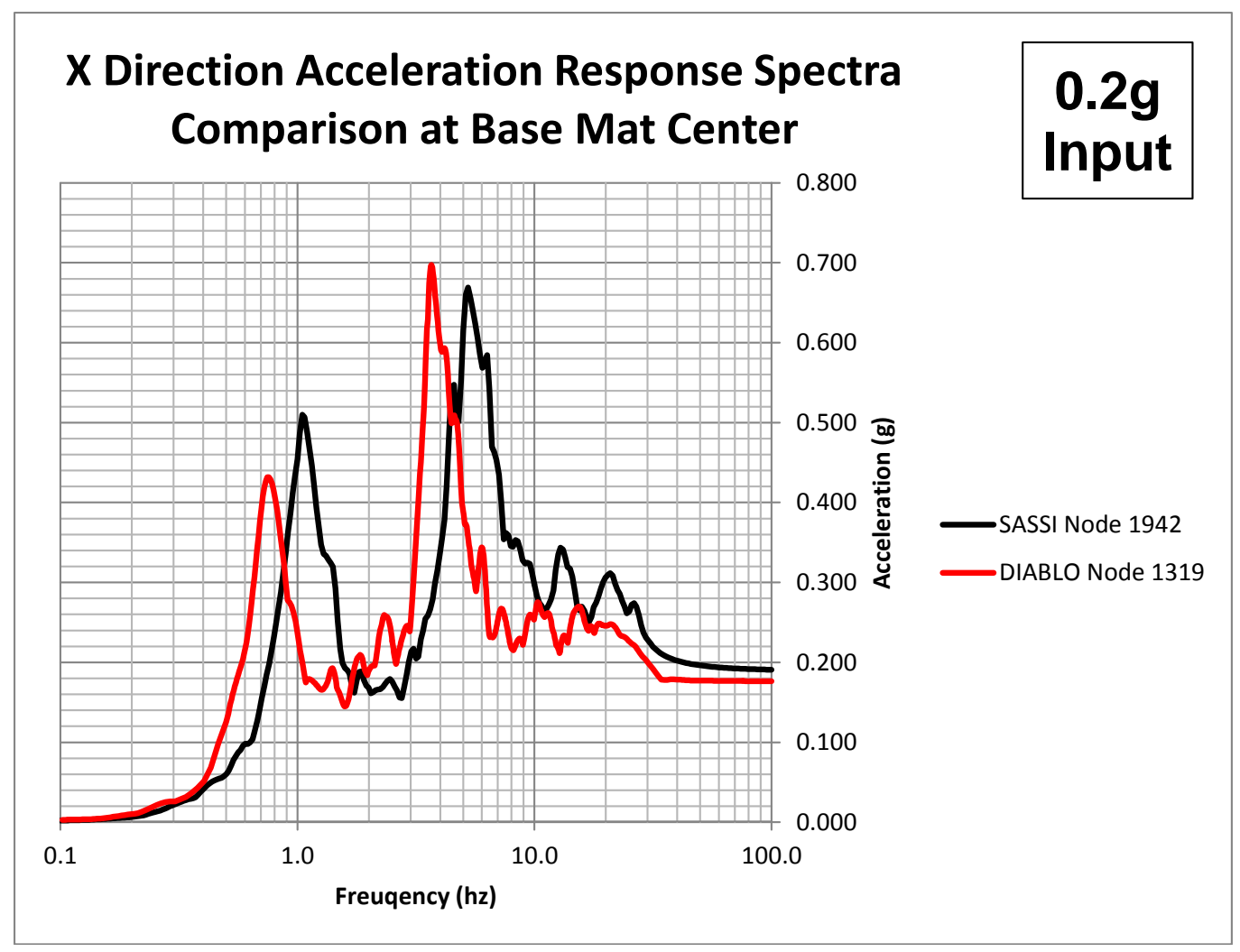

Figure 25 - 5\% damped response spectra, DIABLO(red) v. SASSI(black), 0.2g earthquake level, basemat center, $\mathrm{x}$-direction.

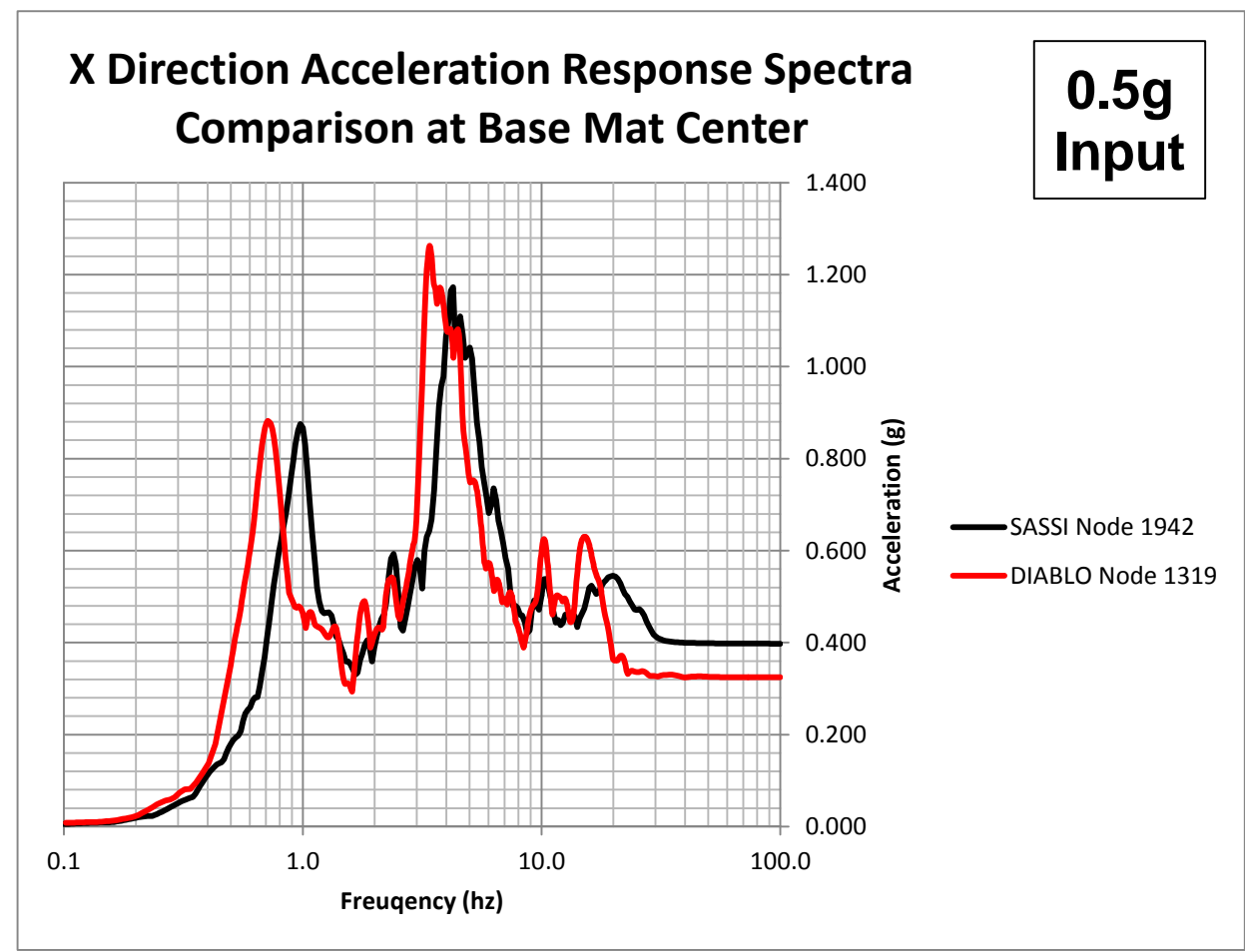

Figure 26: 5\% damped response spectra, DIABLO(red) v. SASSI(black), 0.5g earthquake level, basemat center, $\mathrm{x}$-direction. 


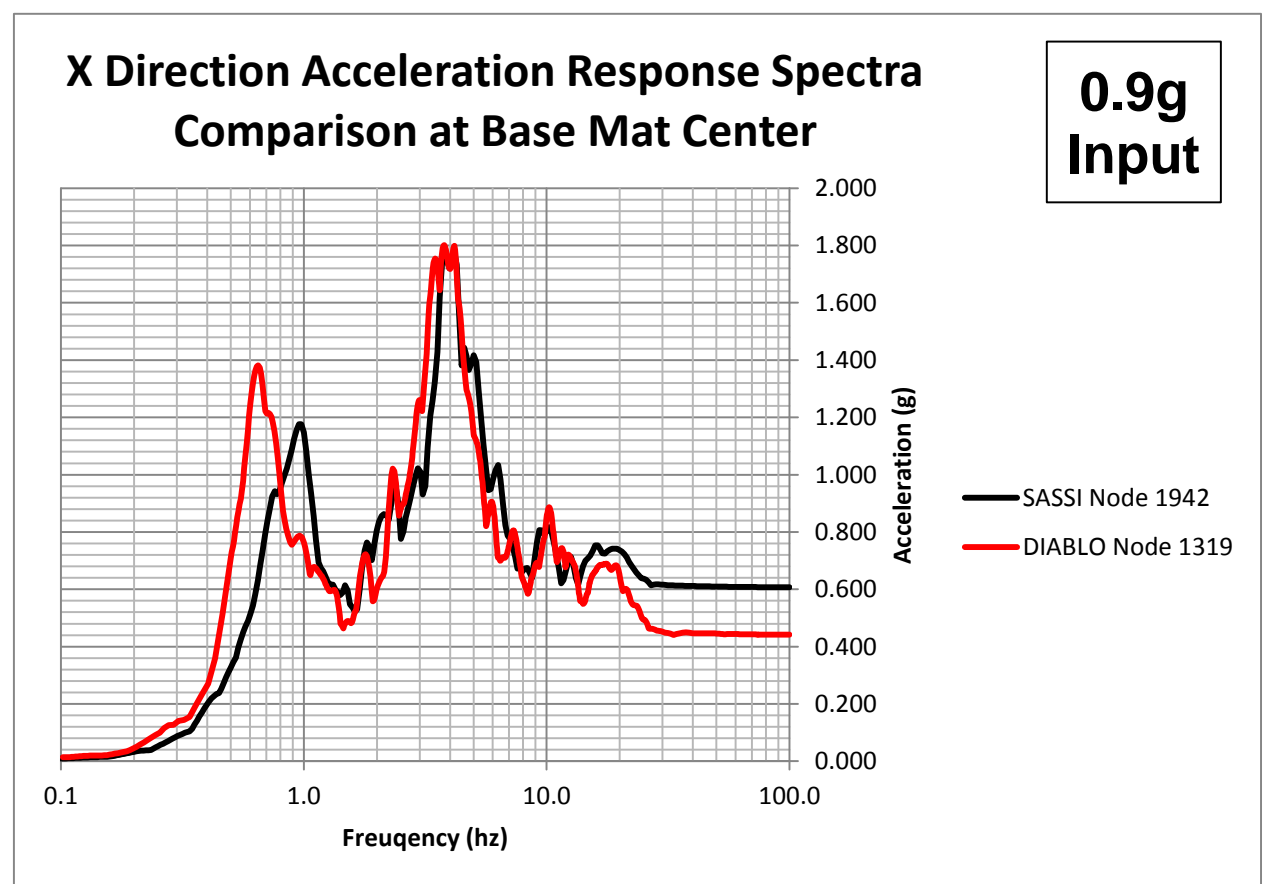

Figure 27 - 5\% damped response spectra, DIABLO(red) v. SASSI(black), $0.9 \mathrm{~g}$ earthquake level, basemat center, $\mathrm{x}$-direction.

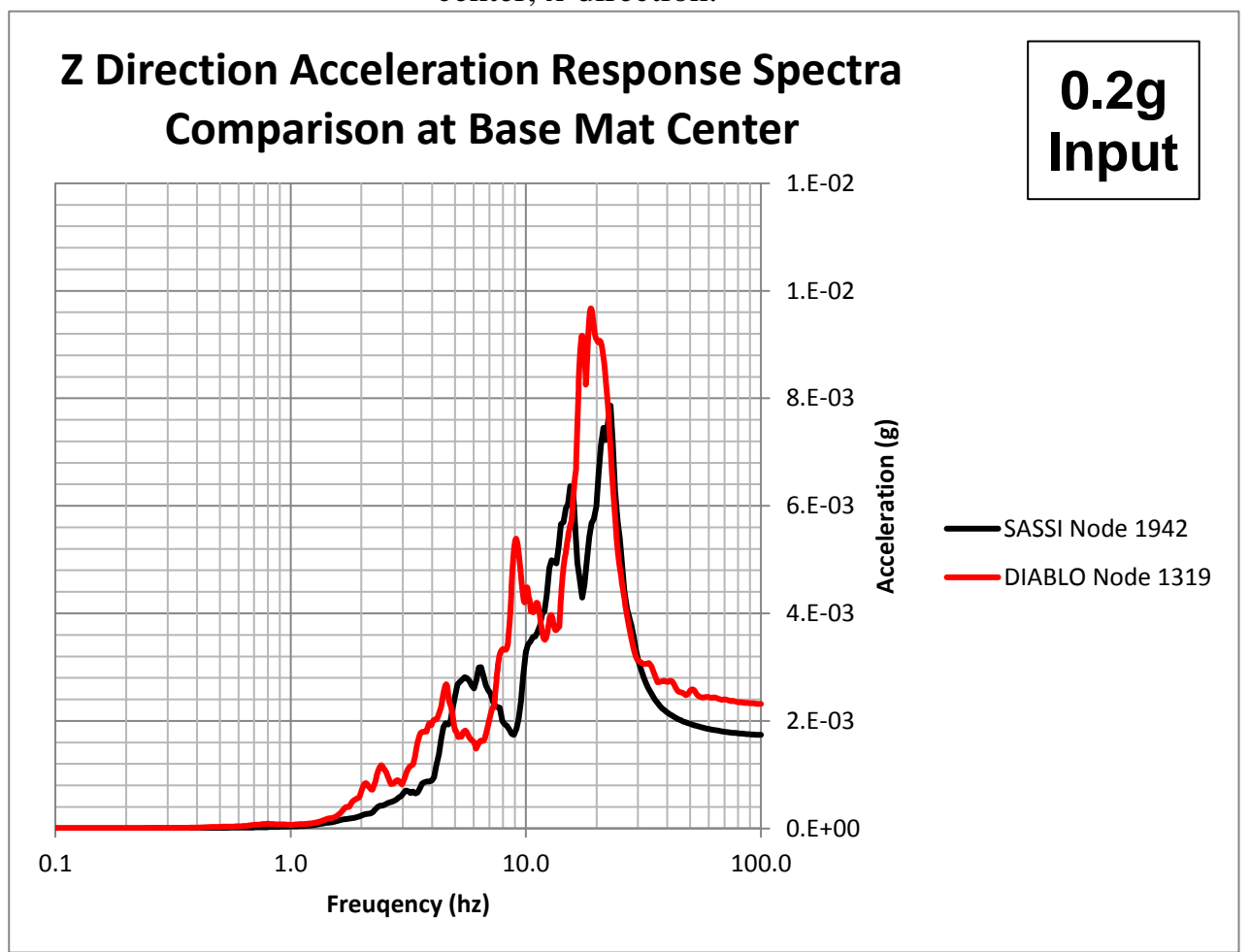

Figure 28 - 5\% damped response spectra, DIABLO(red) v. SASSI(black), 0.2g input, basemat center, zdirection. 


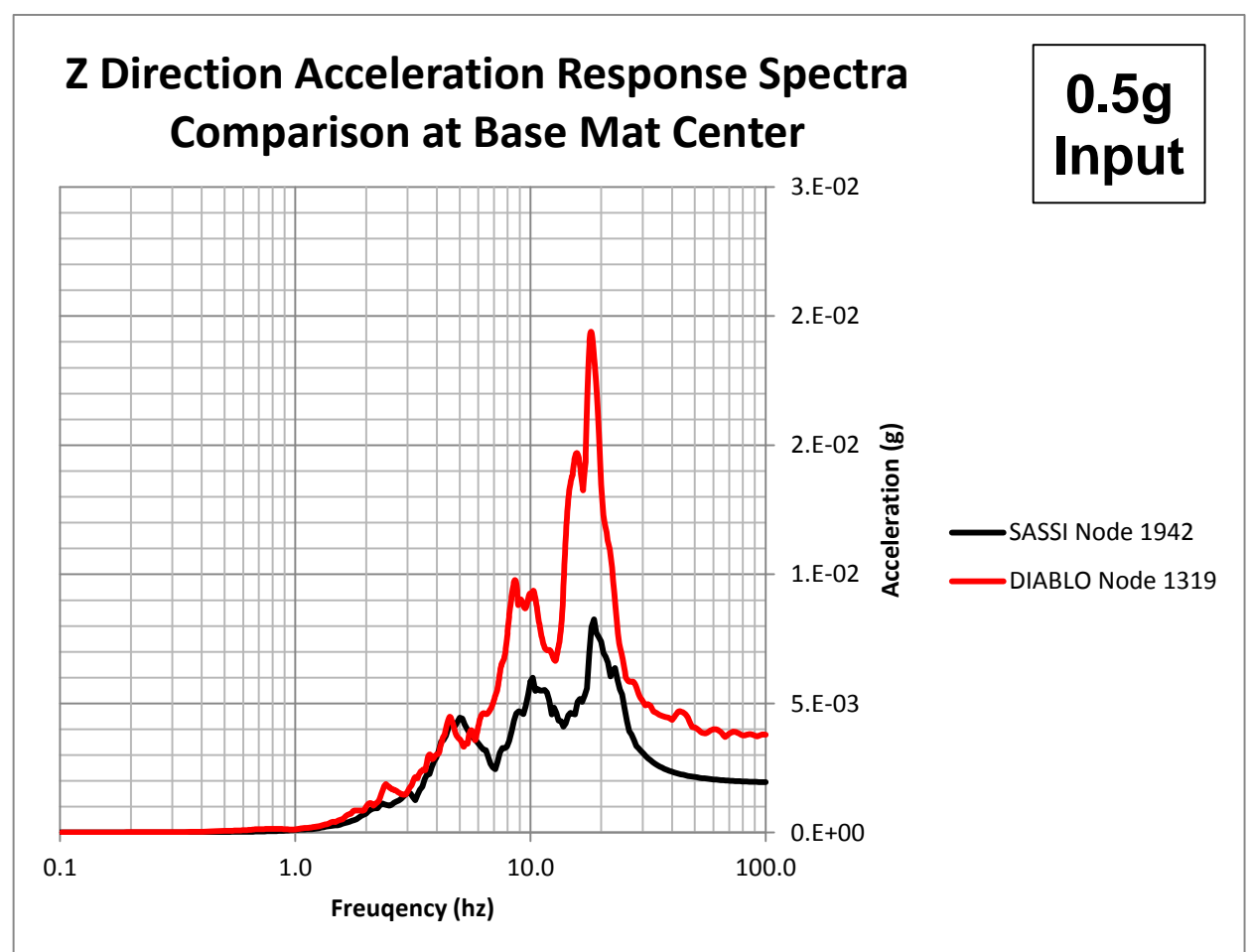

Figure 29 - 5\% damped response spectra, DIABLO(red) v. SASSI(black), $0.5 \mathrm{~g}$ input, basemat center, zdirection.

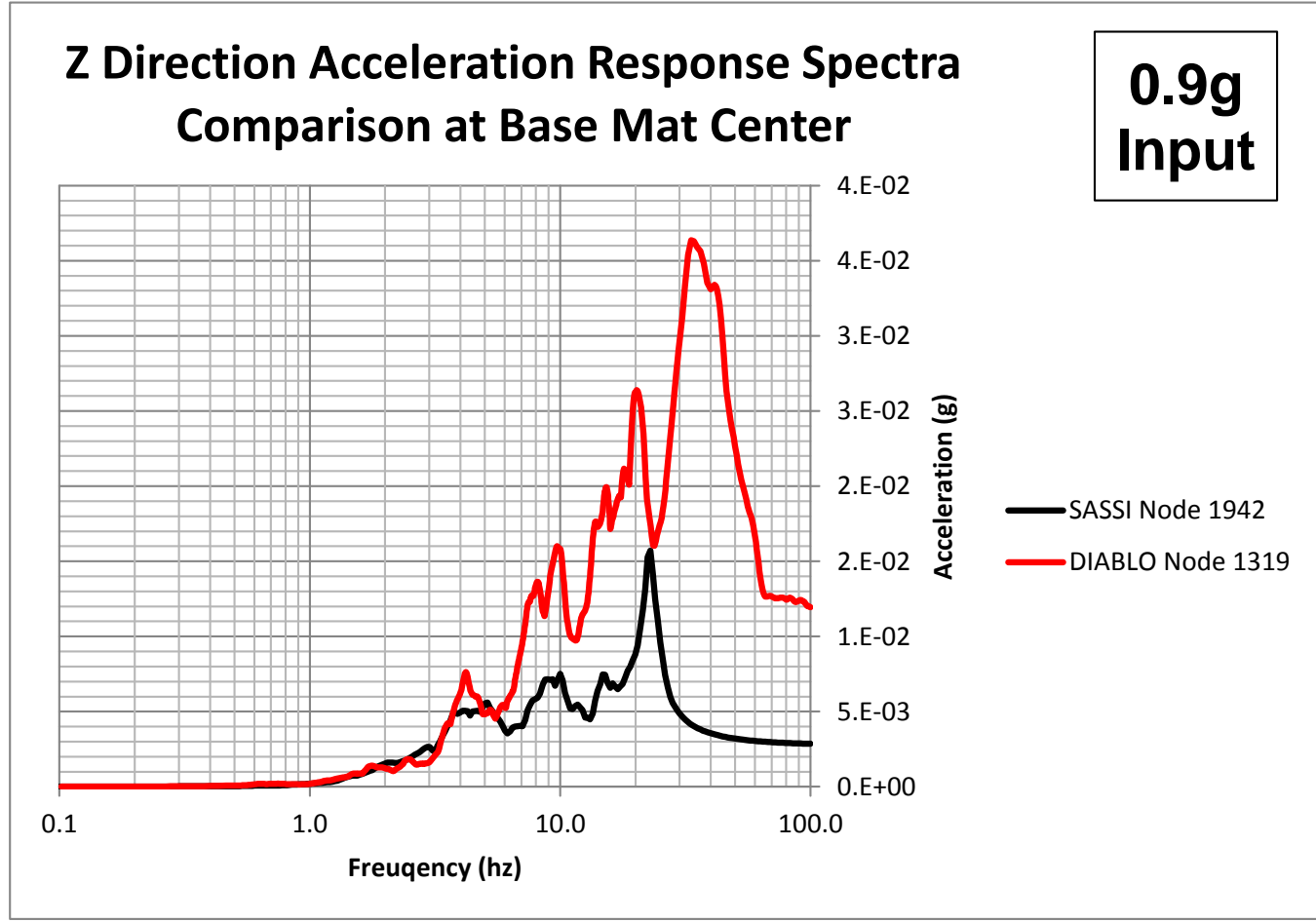

Figure 30- 5\% damped response spectra, DIABLO(red) v. SASSI(black), 0.9g input, basemat center, z-direction. 


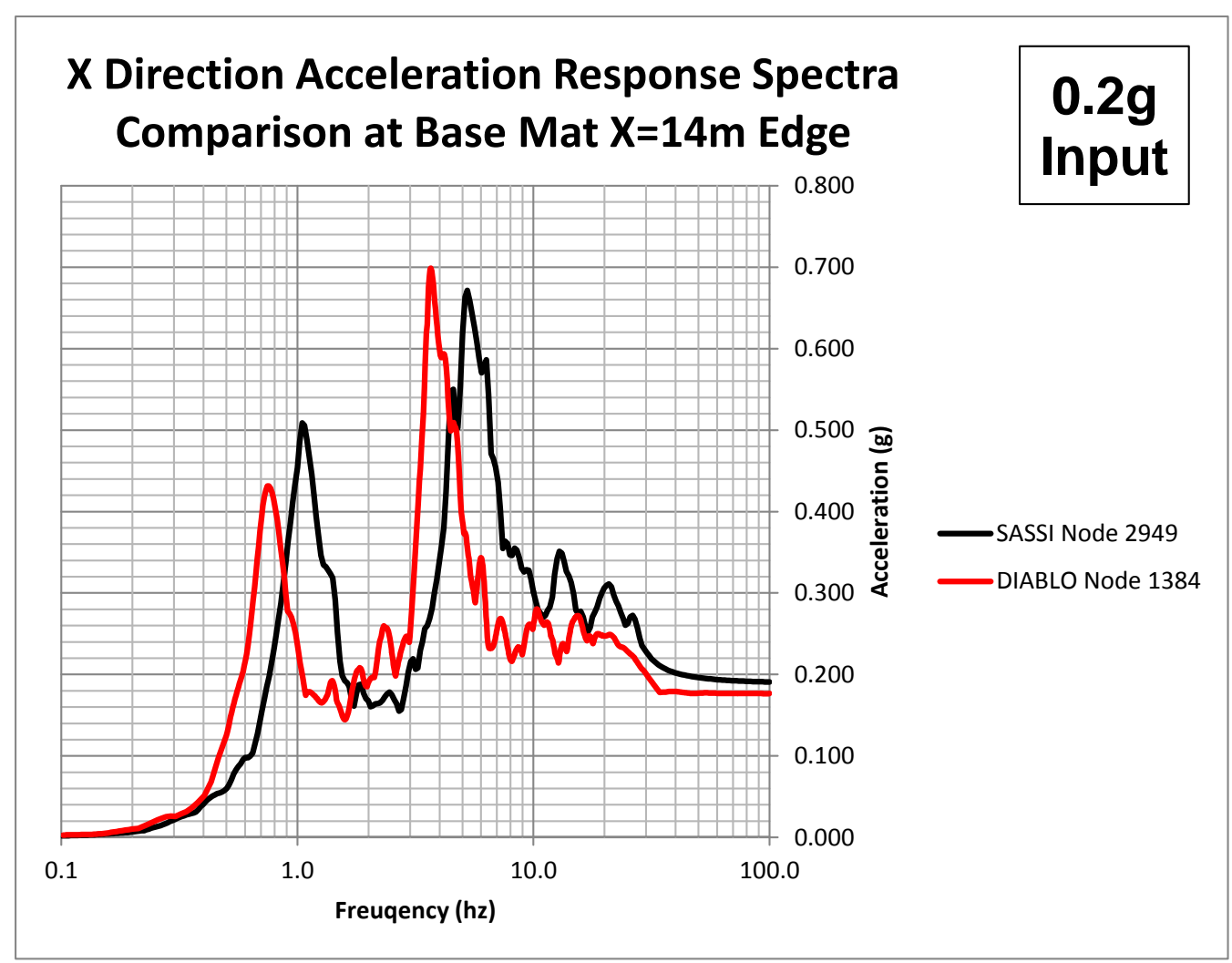

Figure 31- 5\% damped response spectra, DIABLO(red) v. SASSI(black), 0.2g input, basemat $\mathrm{x}=14 \mathrm{~m}$ edge, $\mathrm{x}$-direction. 


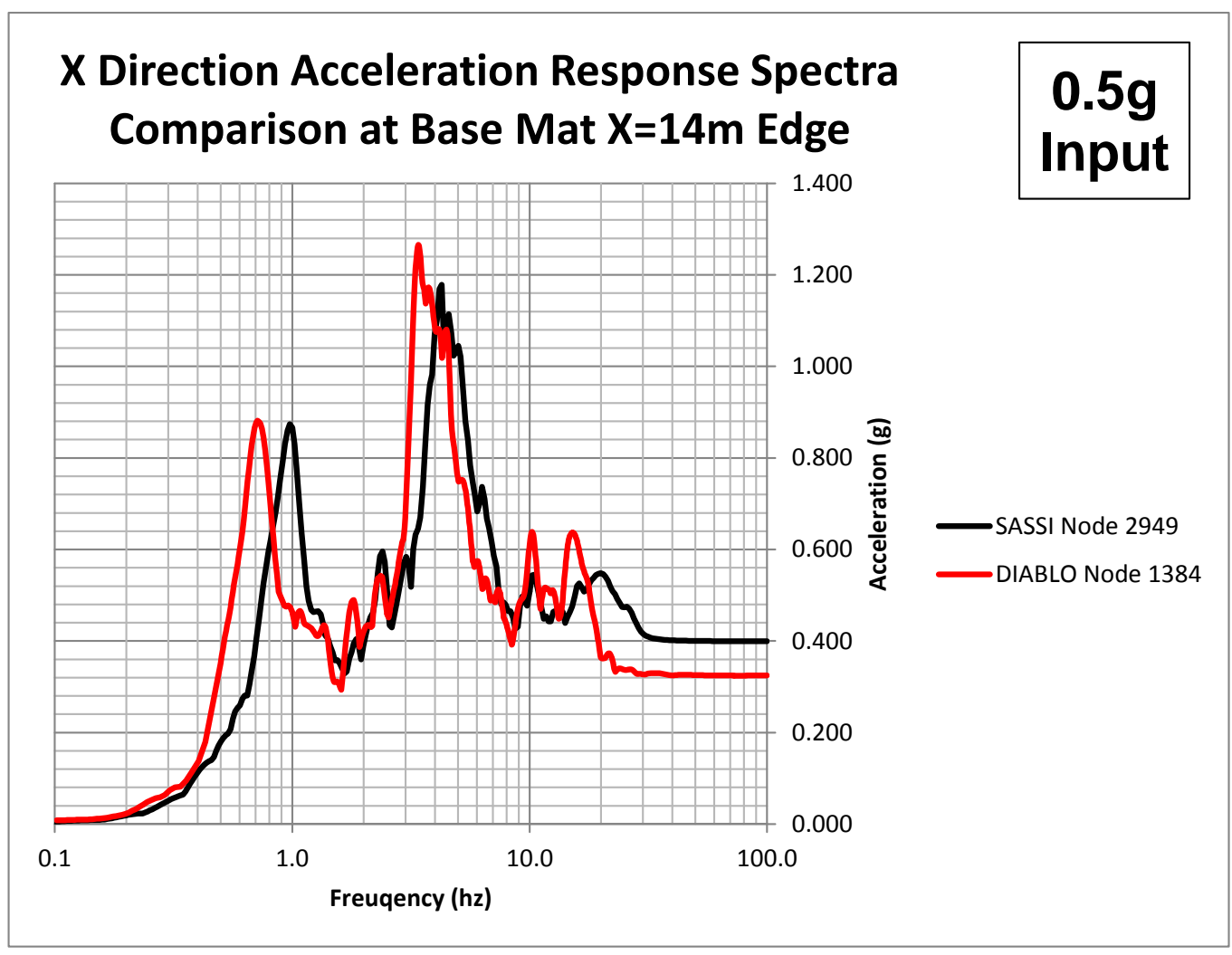

Figure 32 - 5\% damped response spectra, DIABLO(red) vs. SASSI(black), $0.5 \mathrm{~g}$ input, basemat $\mathrm{x}=14 \mathrm{~m}$ edge, $\mathrm{X}$-direction

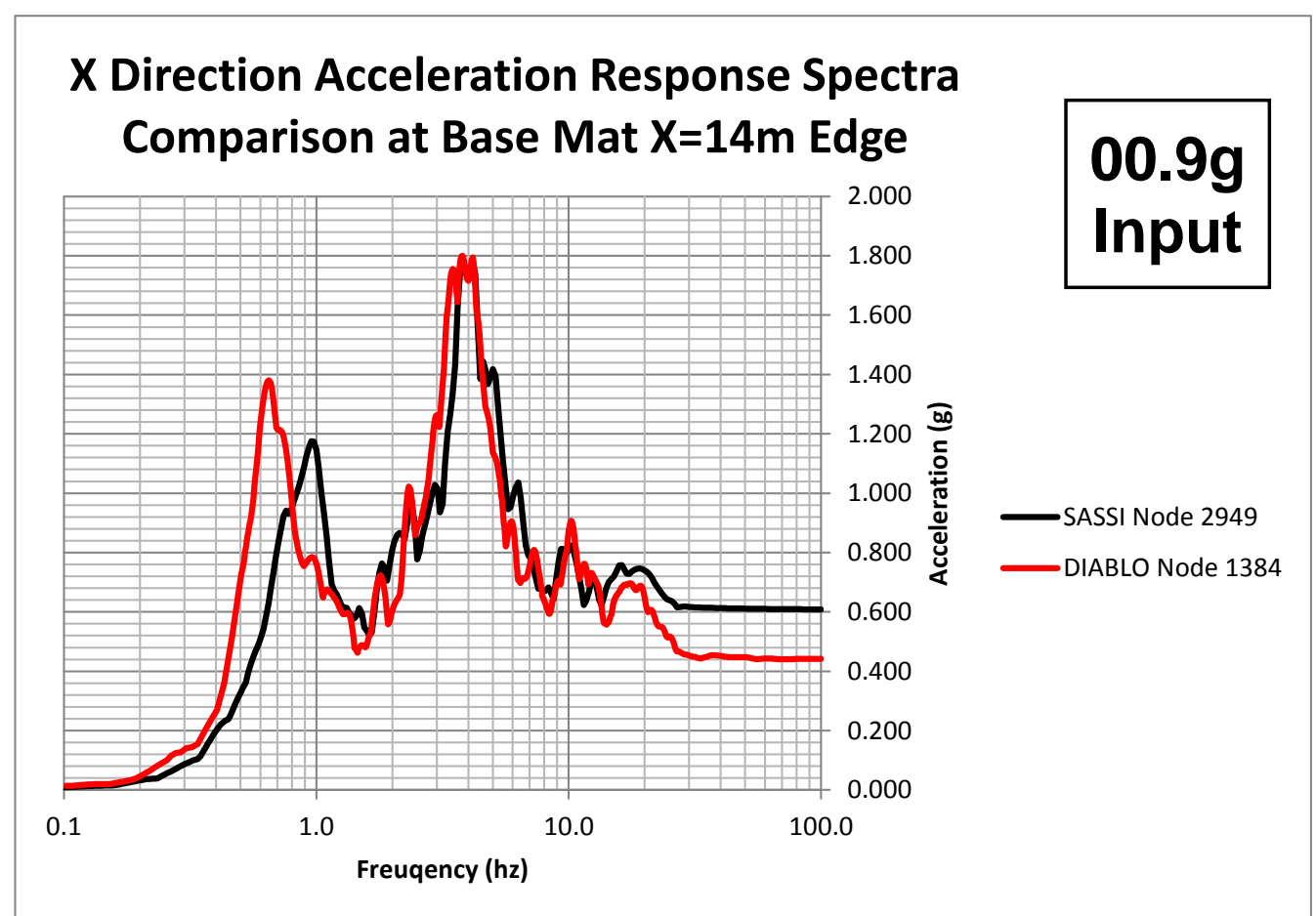

Figure $33-5 \%$ damped response spectra, DIABLO(red) vs. SASSI(black), $0.9 \mathrm{~g}$ input, basemat $\mathrm{x}=14 \mathrm{~m}$ edge, $\mathrm{x}$-direction 


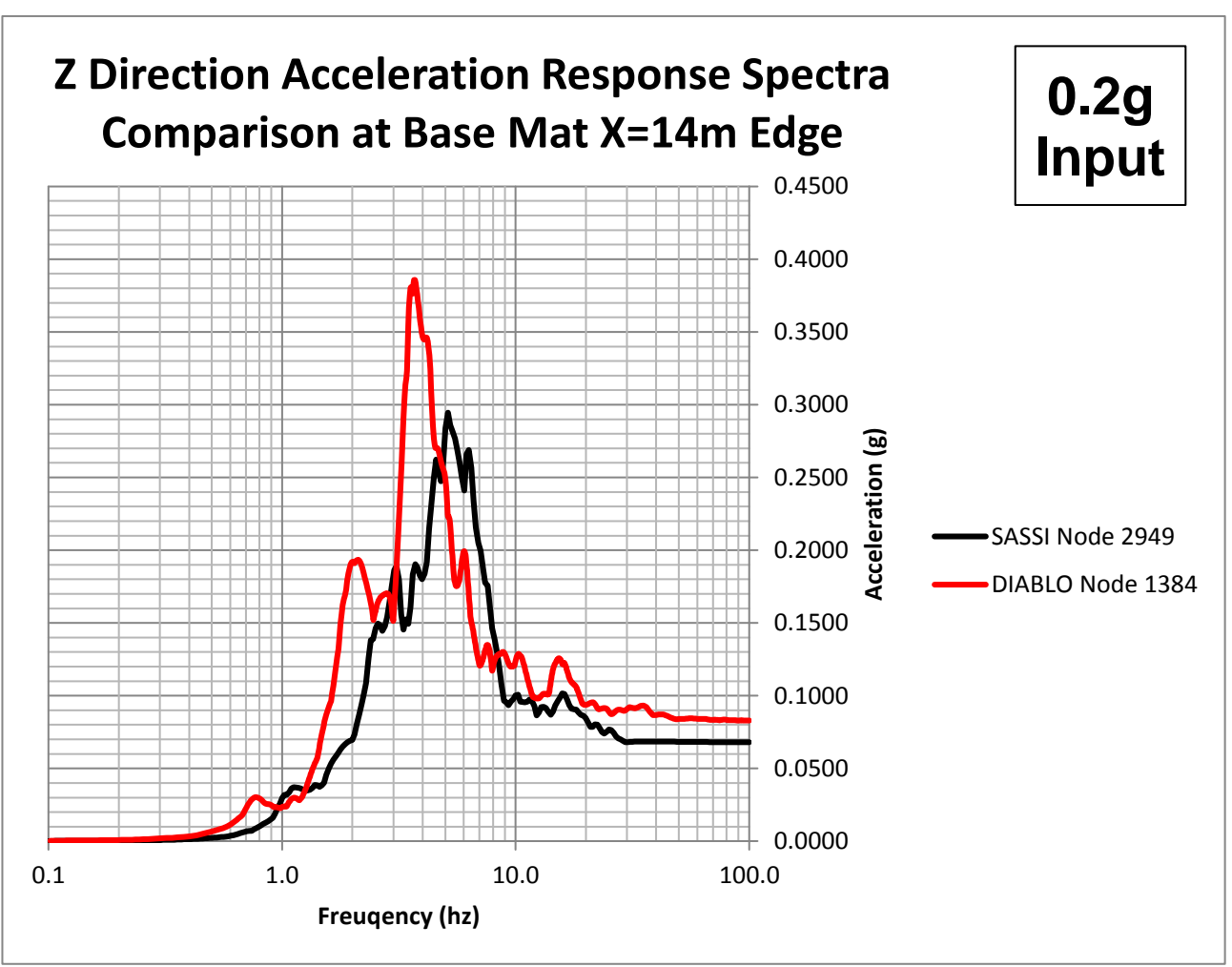

Figure $34-5 \%$ damped response spectra, DIABLO(red) vs. SASSI(black), 0.2g input, basemat $\mathrm{x}=14 \mathrm{~m}$ edge, z-direction 


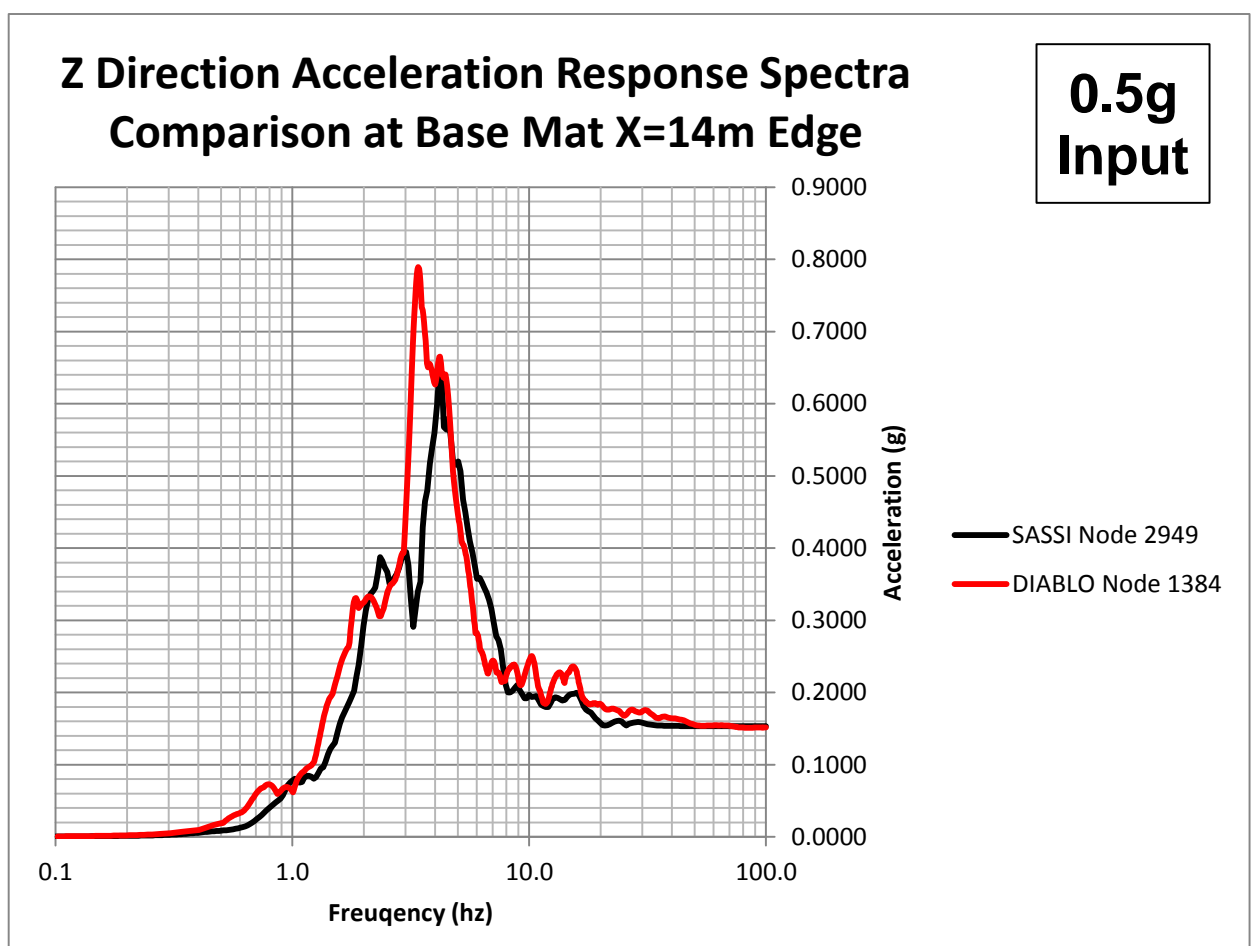

Figure 35 - 5\% damped response spectra, DIABLO(red) vs. SASSI(black), $0.5 \mathrm{~g}$ input, basemat $\mathrm{x}=14 \mathrm{~m}$ edge, z-direction

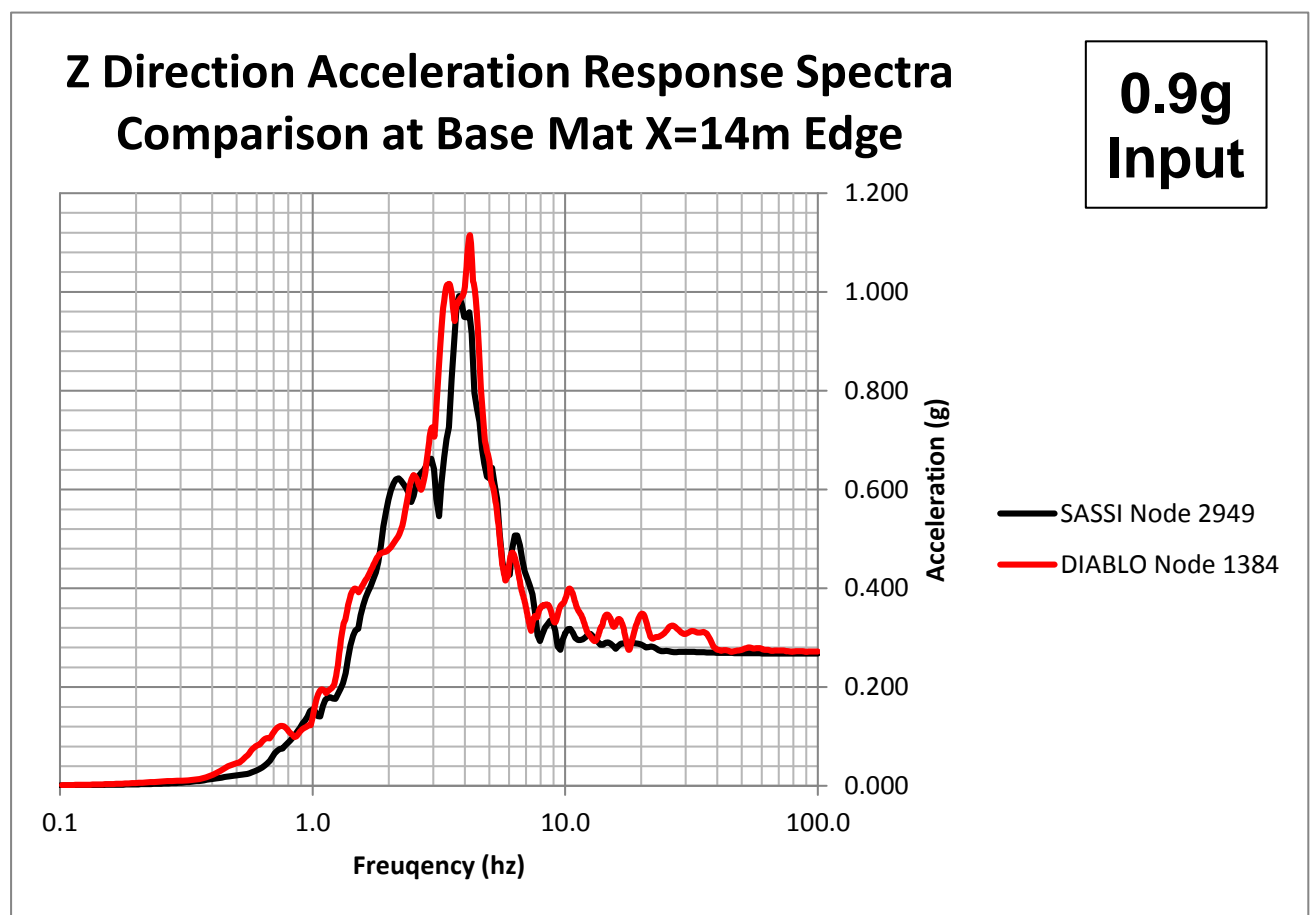

Figure 36 -- 5\% damped response spectra, DIABLO(red) vs. SASSI(black), 0.9g input, basemat $\mathrm{x}=14 \mathrm{~m}$ edge, $\mathrm{z}$-direction 


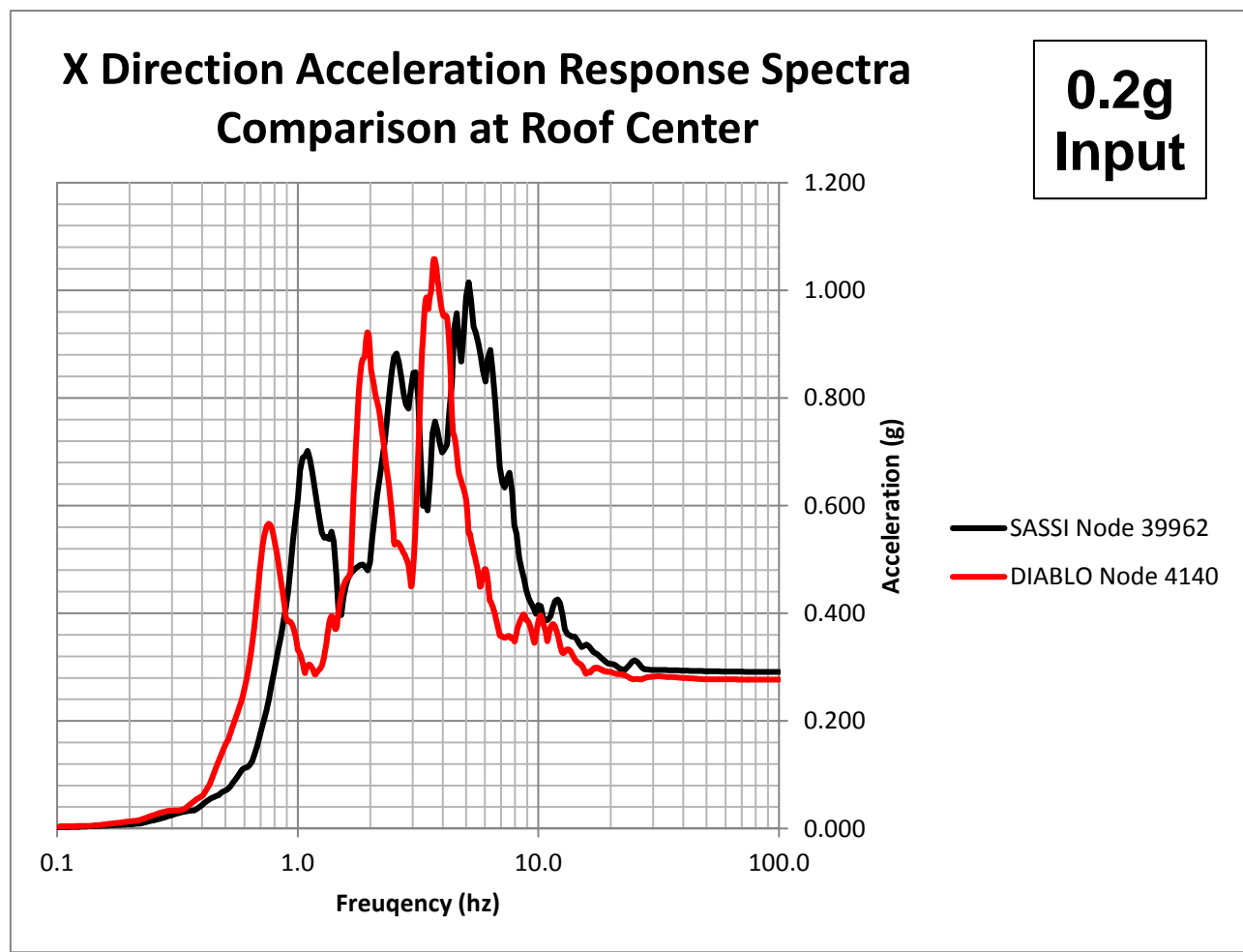

Figure 37 -- 5\% damped response spectra, DIABLO(red) vs. SASSI(black), 0.2g input, roof center, $\mathrm{x}$ direction

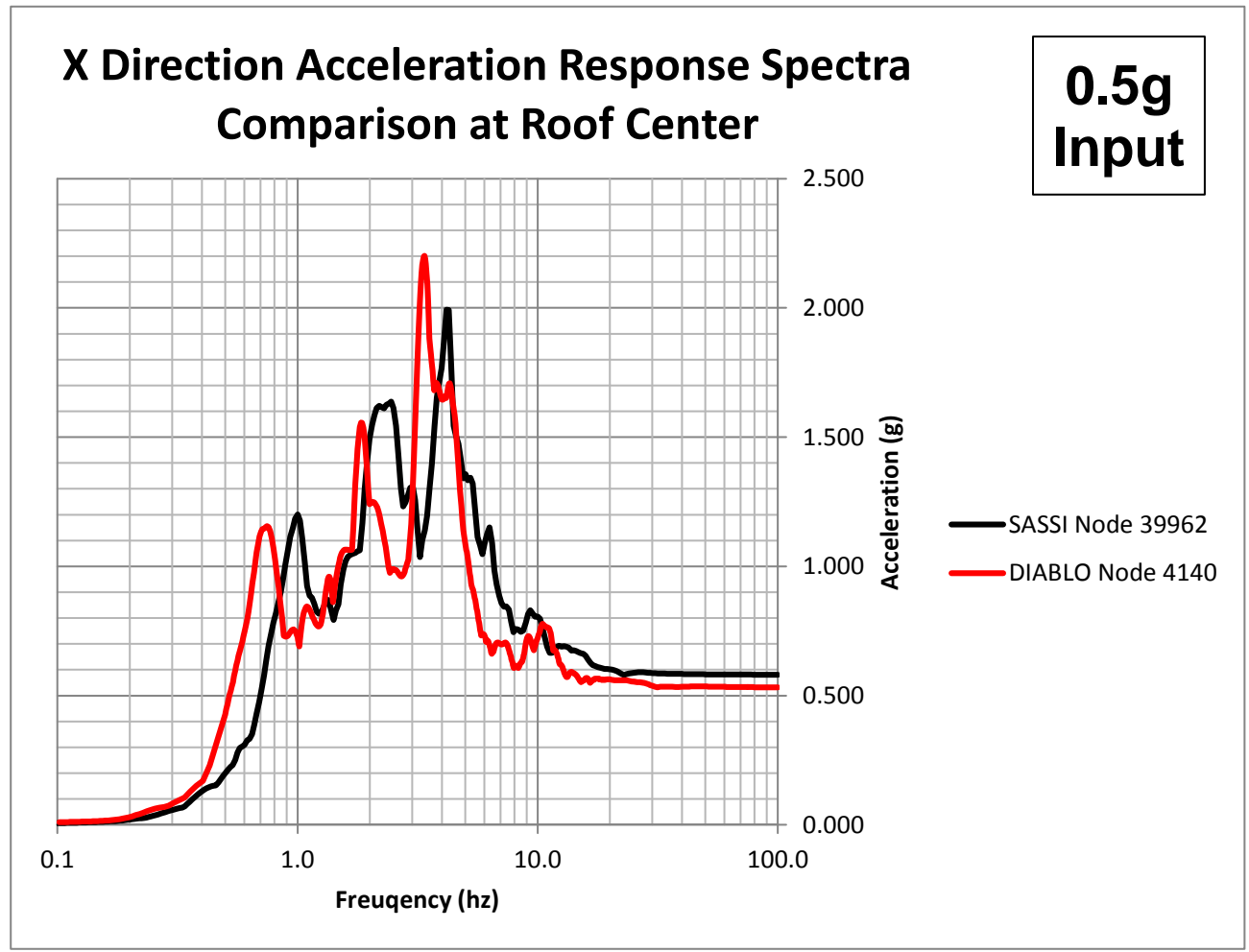

Figure 38 - 5\% damped response spectra, DIABLO(red) vs. SASSI(black), 0.5g input, roof center, $\mathrm{x}-$ direction. 


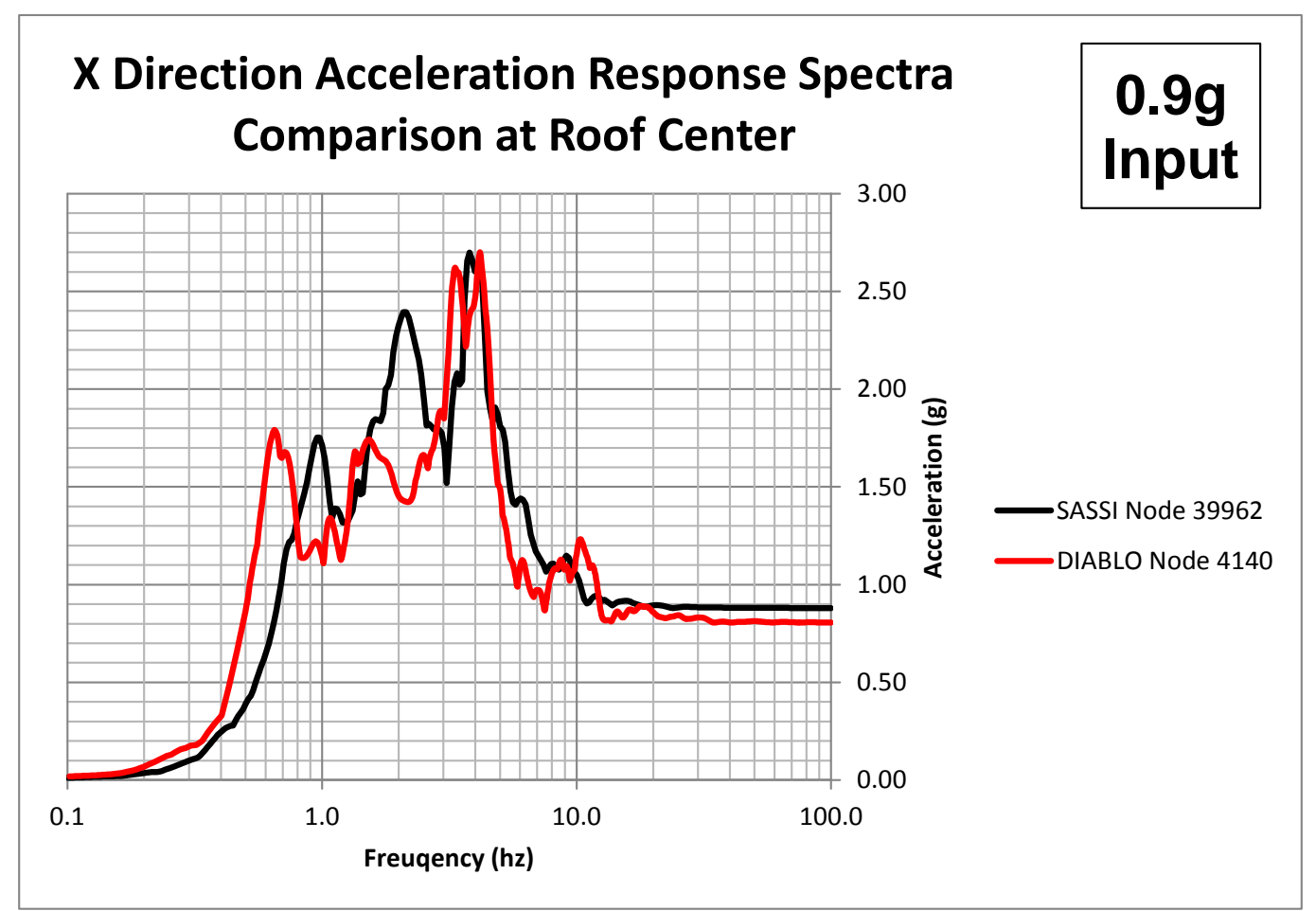

Figure 39 - 5\% damped response spectra, DIABLO (red) vs. SASSI (black), 0.9g input, roof center, $\mathrm{x}-$ direction.

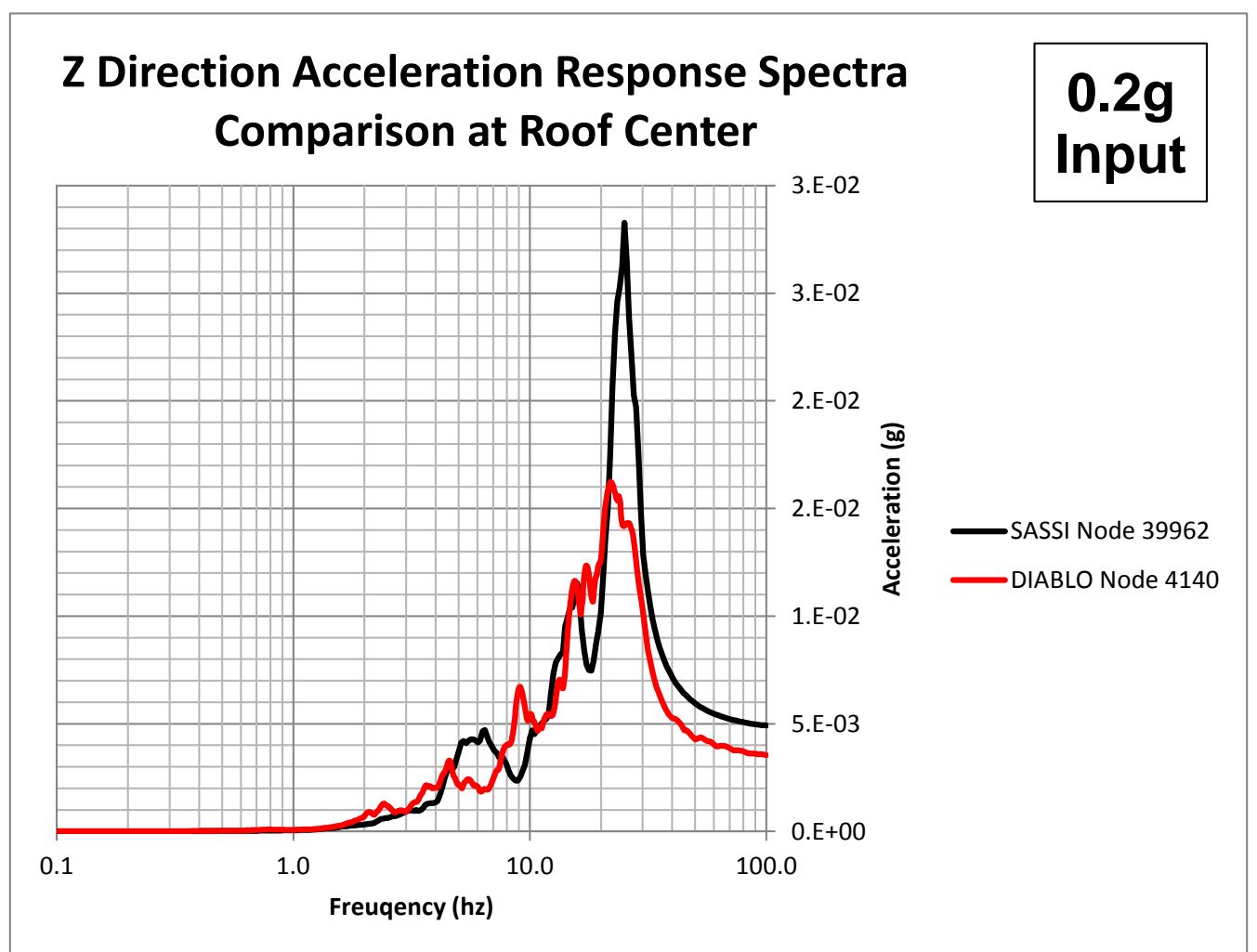

Figure 40 - 5\% damped response spectra, DIABLO (red) vs. SASSI (black), 0.2g input, roof center, zdirection. 


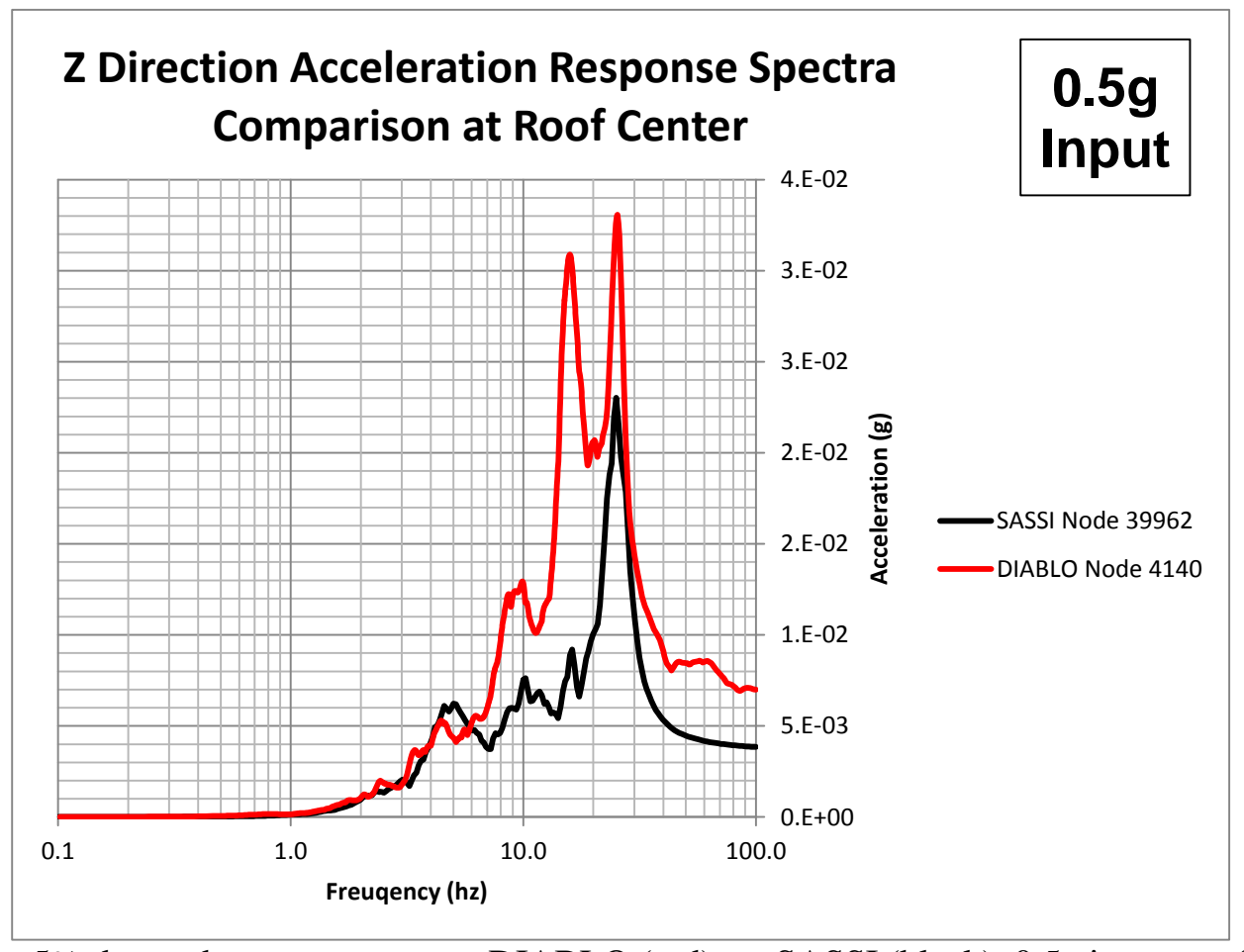

Figure 41 - 5\% damped response spectra, DIABLO (red) vs. SASSI (black), 0.5g input, roof center, zdirection.

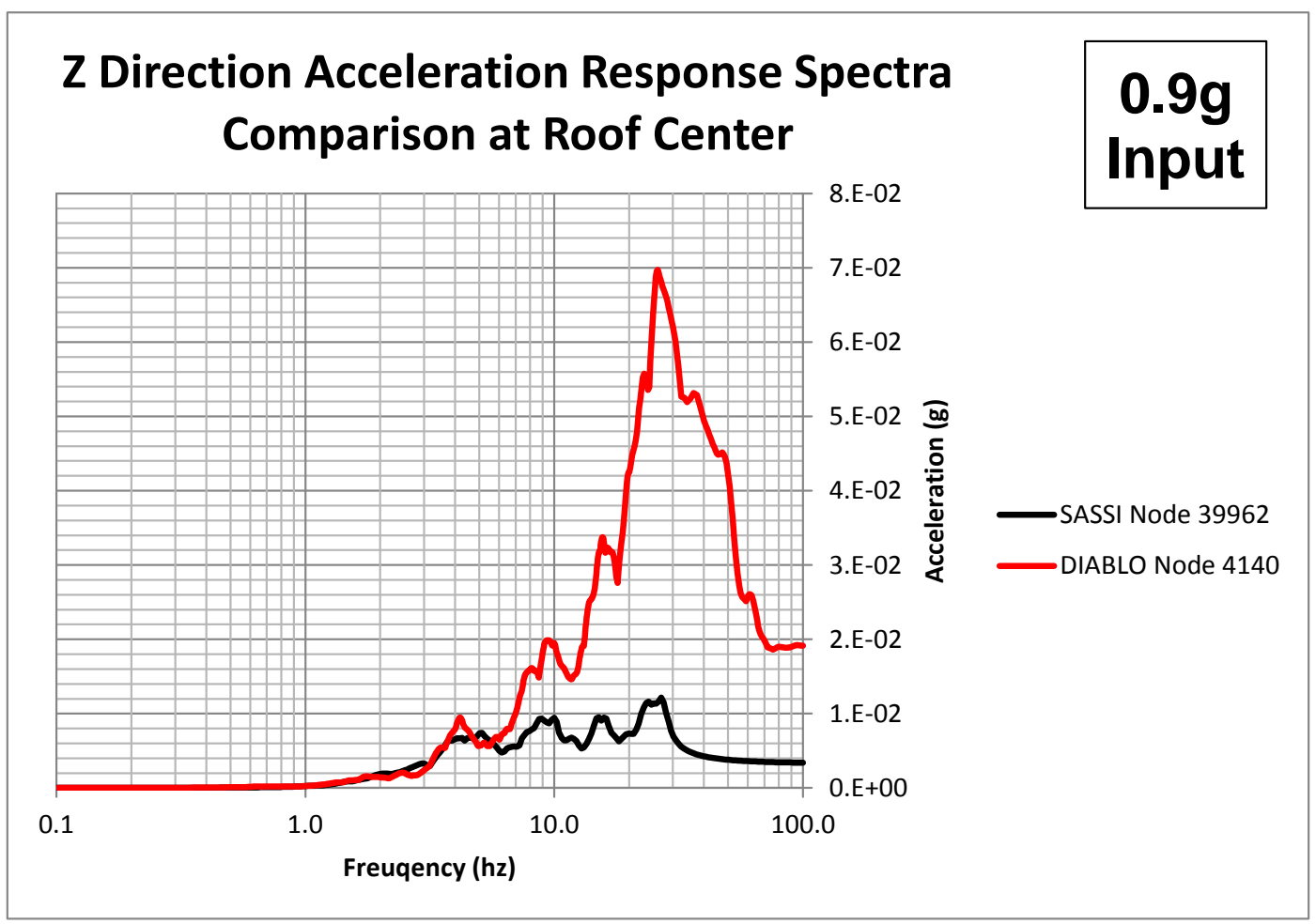

Figure 42 - 5\% damped response spectra, DIABLO (red) vs. SASSI (black), 0.9g input, root center, zdirection. 


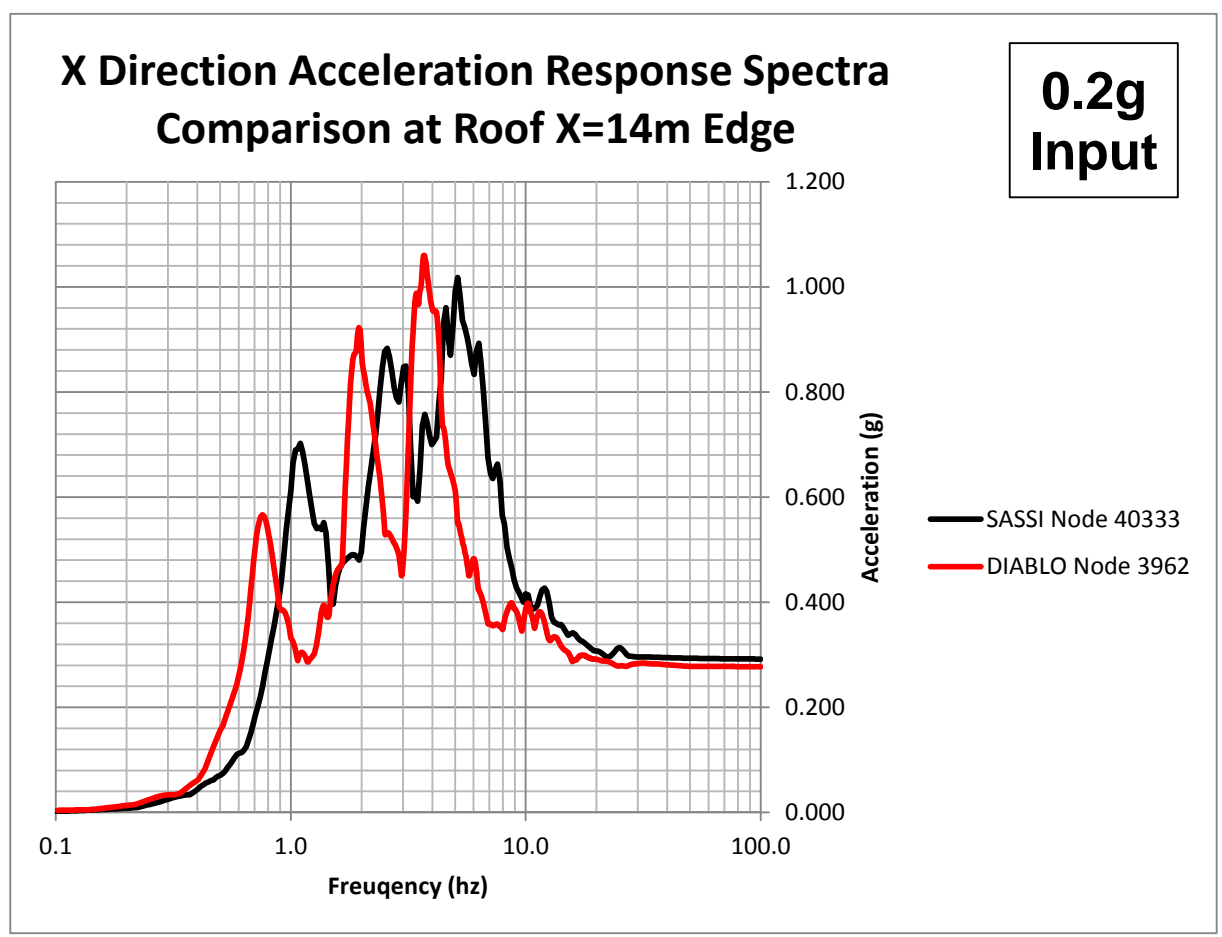

Figure 43 - 5\% damped response spectra, DIABLO (red) vs. SASSI (black), 0.2g input, roof x-14m edge, $\mathrm{x}$-direction.

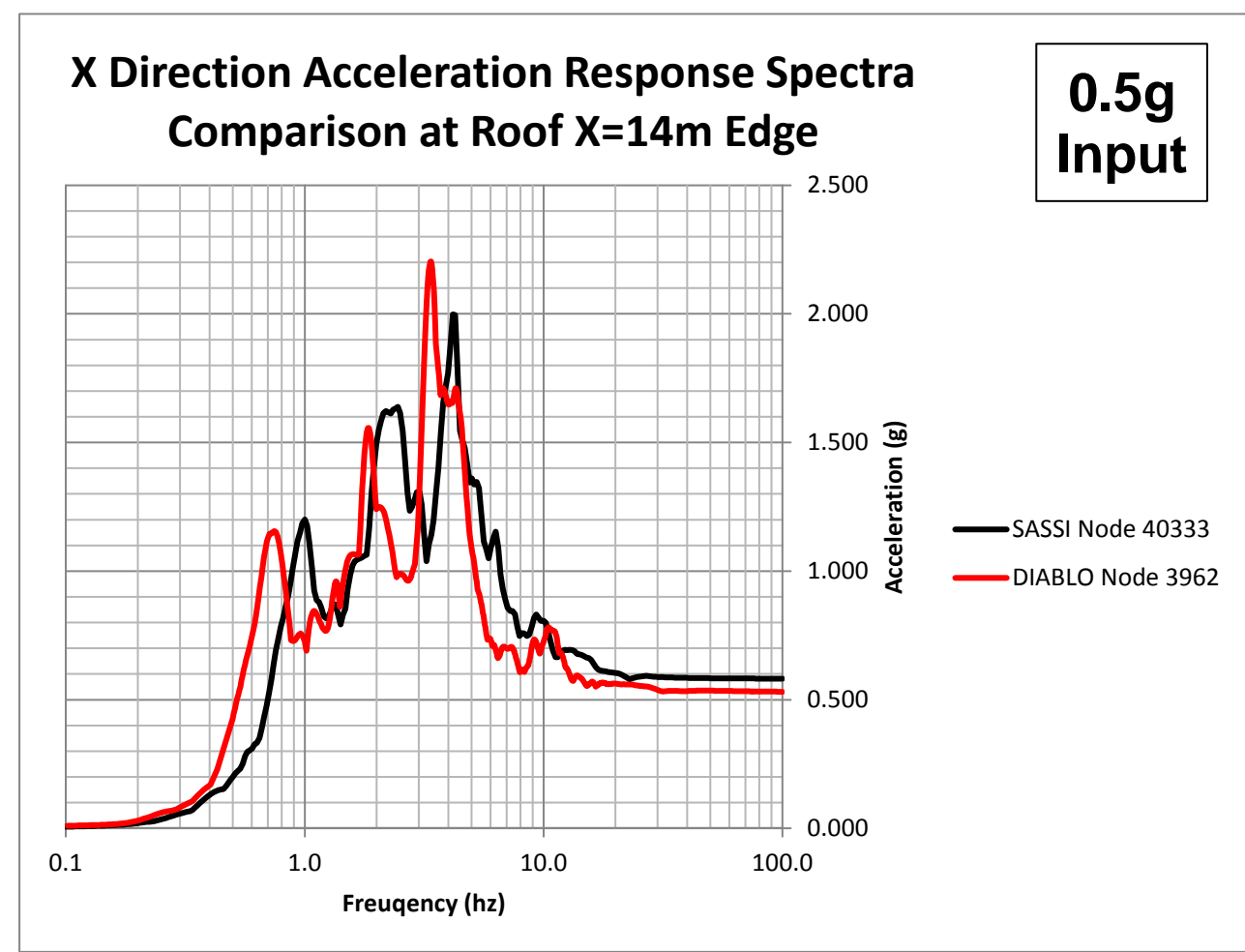

Figure 44 - - 5\% damped response spectra, DIABLO (red) vs. SASSI (black), $0.5 \mathrm{~g}$ input, roof $\mathrm{x}=14 \mathrm{~m}$ edge, $\mathrm{x}$-direction. 


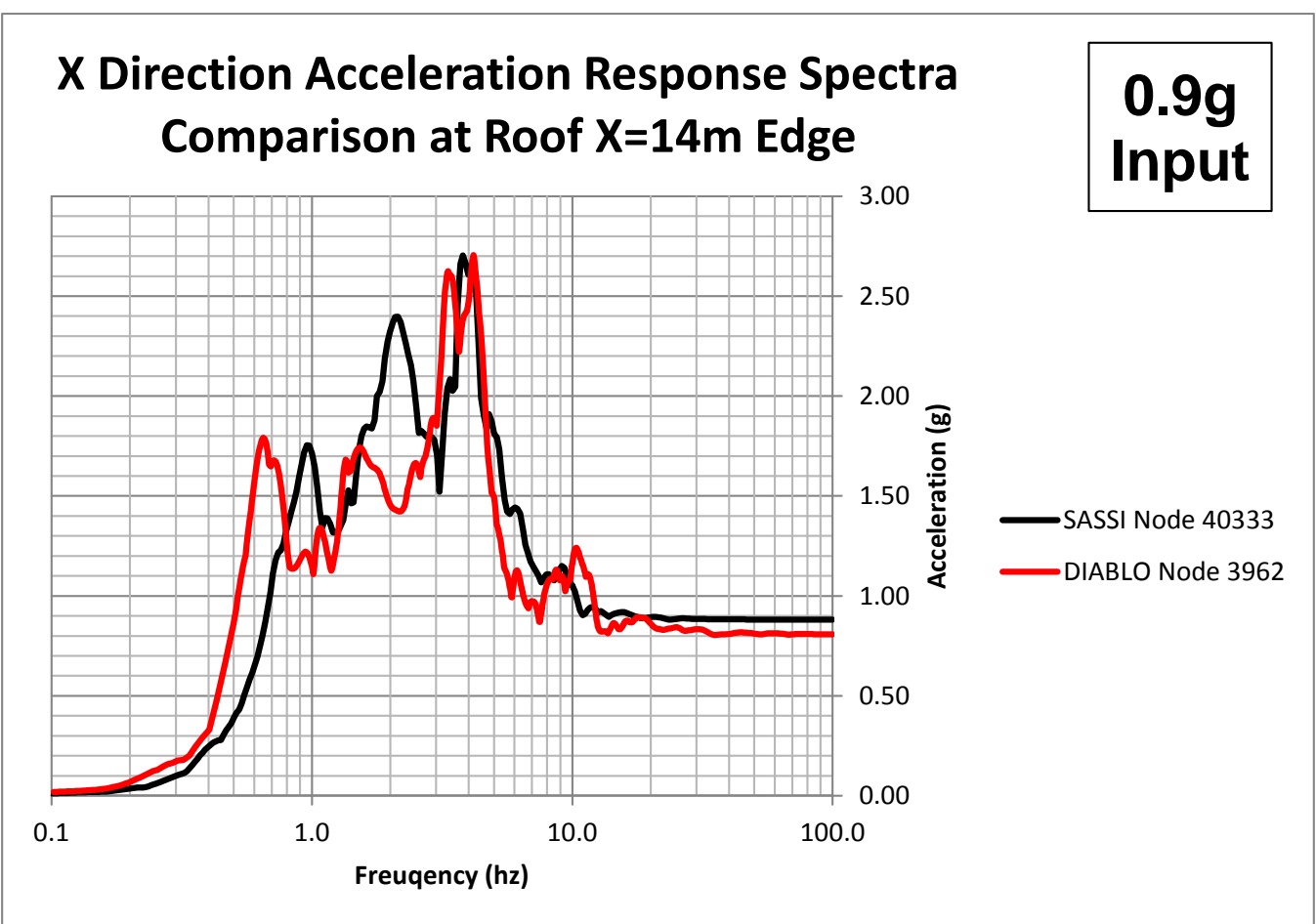

Figure 45 - 5\% damped response spectra, DIABLO (red) vs. SASSI (black), $0.9 \mathrm{~g}$ input, roof $\mathrm{x}=14 \mathrm{~m}$ edge, $\mathrm{x}$-direction. 


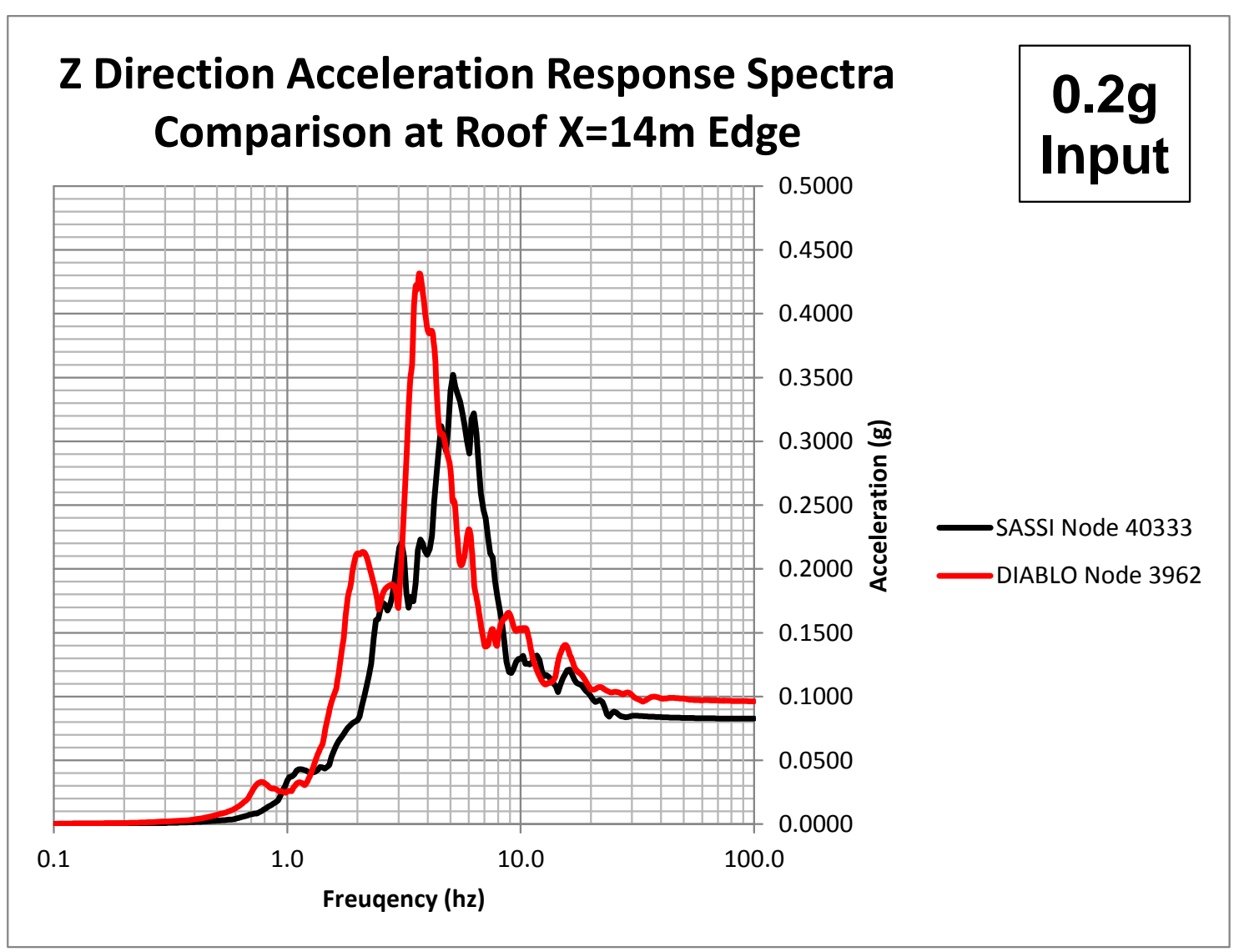

Figure 46- 5\% damped response spectra, DIABLO (red) vs. SASSI (black), $0.2 \mathrm{~g}$ input, roof $\mathrm{x}=14 \mathrm{~m}$ edge, z-direction. 


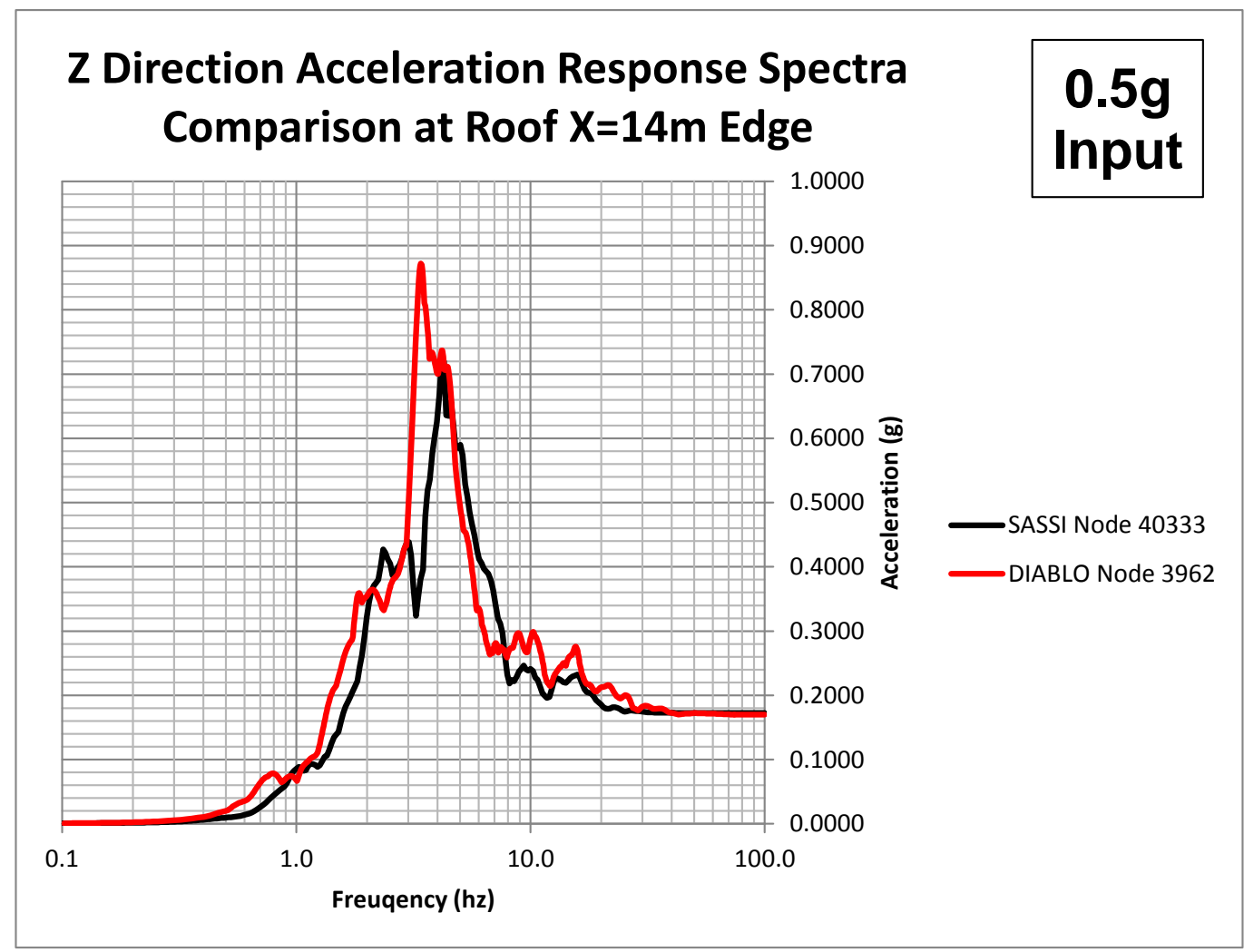

Figure 47 - 5\% damped response spectra, DIABLO (red) vs. SASSI (black), $0.5 \mathrm{~g}$ input, roof $\mathrm{x}=14 \mathrm{~m}$ edge, z-direction.

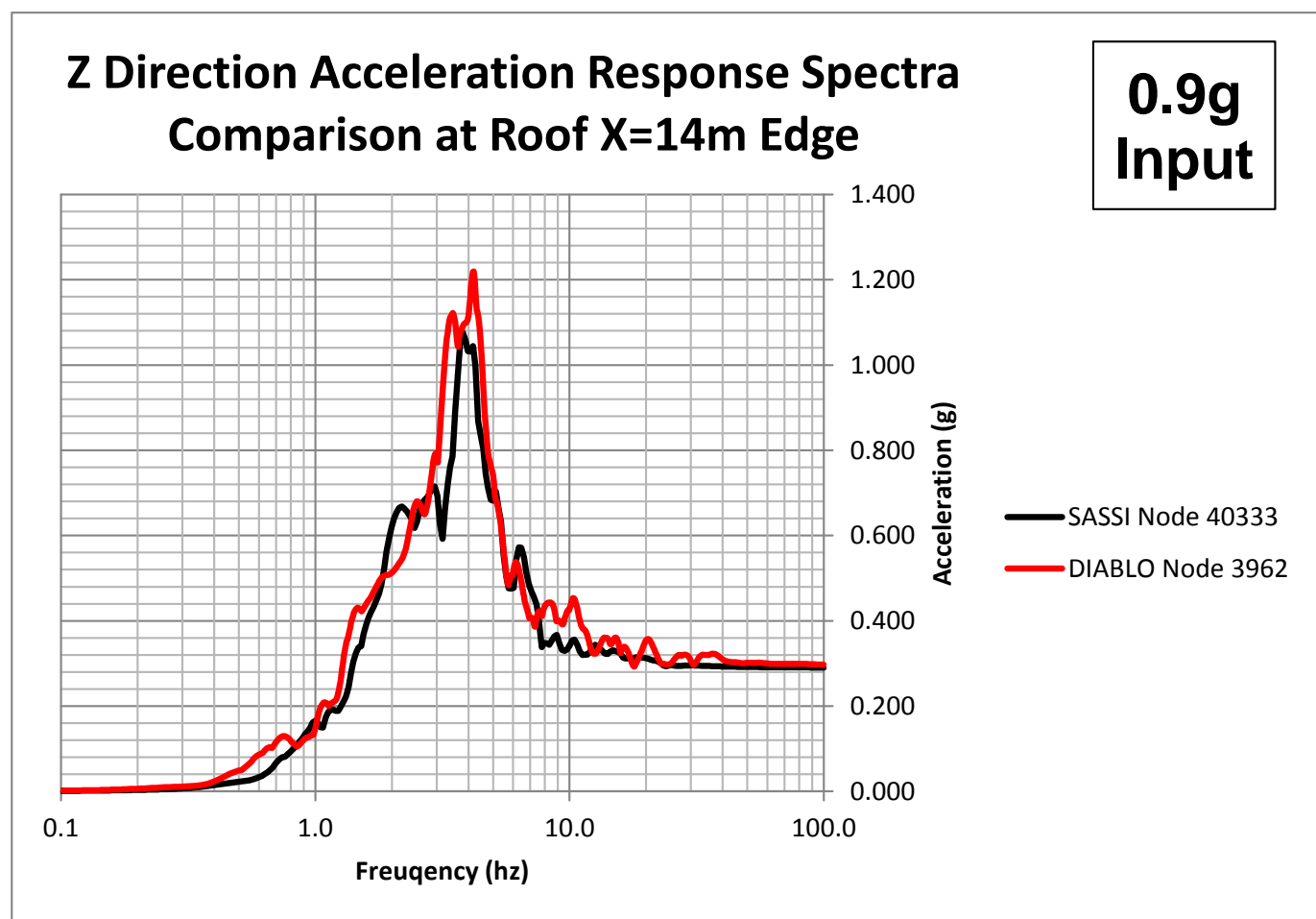

Figure 48 - 5\% damped response spectra, DIABLO (red) vs. SASSI (black), 0.9g input, roof $\mathrm{x}=14 \mathrm{~m}$ edge, z-direction. 


\section{SUMMARY AND CONCLUSION}

A method for the time-domain analysis of soil-structure interaction was developed, based on extension of the domain reduction methodology developed by Bielak and coworkers. The extension includes a modified strain measure in the intermediate layer, and is valid for intermediate layers more than one element thick. The method was combined with a simple nonlinear material model based upon the Ramberg-Osgood formulation, and compared to the current state-of-the-art frequency-domain codes SHAKE/CARES (for a 1-D soil column) and SASSI (for full 3-D analysis of a small modular reactor). The method compares well to the current frequency-domain approach, but important differences are found as well. Ultimately, for a more perfect match with SASSI a material model that more closely approximates the constant-modulus/constant damping representation used in SASSI would be necessary. However, the methodology is well-suited toward the investigation of more sophisticated (and accurate) material models and geometric nonlinearities, which should ultimately lead to a more consistent representation of soil/structure interaction. Future work (time and funding permitting) will include evaluation of more sophisticated nonlinear material models, as well as contact/impact models for investigation of raft uplift effects.

\section{ACKNOWLEDGEMENTS}

This work was supported by the NEAMS program, DOE Office of Nuclear Energy (NE-41). Lawrence Livermore National Laboratory is operated by Lawrence Livermore National Security, LLC, for the benefit of the U.S. Department of Energy, National Nuclear Security Administration, Contract DE-AC52-07NA27344. The authors would like to thank Prof. Boris Jeremic (U.C. Davis) for initially pointing us towards Prof. Bielak's work, Professor Carl Costantino for the CARES runs, and Dr.'s Joseph Braverman and Jinsuo Nie for performing SASSI runs on the notional SMR. The authors would also like to thank Dr. Mike Gerhard (Lawrence Livermore National Laboratory) for helping us with formatting various plots.

\section{REFERENCES}

Assimaki, D., \& Kausel, E. (2002). An equivalent linear algorithm with frequency- and pressuredependent moduli and damping for the seismological analysis of deep sites. Soil Dynamics and Earthquake Engineering, 22, 950-965.

Bielak, J., Loukakis, K., Hisada, Y., \& Yoshimura, C. (2003, April). Domain Reduction Method for Three-Dimensional Earthquake Modeling in Localized Regions, Part I: Theory. Bulletin of the Seismological Society of America, 93(No. 2), 817-824.

Bonilla, L. F., Archuleta, R. J., \& Lavallee, D. (2005, December). Hysteretic and Dilatant Behavior of Cohesionless Soils and Their Effects on Nonlinear Site Response: Field Data Observations and Modeling. Bulletin of the Seismological Society of America, 95(6), 2373-2395.

Costantino, C. J., Miller, C., \& Xu, J. (1995). CARES: Computer Analysis for Rapid Evaluation of Structures Version 1.2. Monsey, N.Y.: Constantino, Miller and Associates.

Crandall, S. H. (1970). The Role of Damping in Vibration Theory. Journal of Sound and Vibration, 11(1), 3-18.

Drosos, V. A., Gerolymos, N., \& Gazetas, G. (2012). Constitutive model for soil amplification of ground shaking: Parameter calibration, comparisons, validation. Soil Dynamics and Earthquake Engineerg, 42, 255-274. 
EPRI. (1993). Guidelines for determining design basis ground motions, Final Report. Electric Power Research Institute (EPRI).

Idriss, I. M., Sun, J. I., Schnabel, P., Lysmer, J., \& Seed, H. B. (1992). Users Manual for SHAKE 91, A Computer Program for Conductiving Equivalent Linear Seismic Response Analyses of Horizontally Layered Soil Deposits. Building and Fire Research Laboratory,, Structures Division. Gainsville, Maryland: National Institute of Standards.

Matasovic, N., \& Vucetic, M. (1993, November). Cyclic Characterization of Liquifiable Sands. Journal of Geotechnical Engineering, 119(11), 1805-1822.

Ostadan, F. (2007, April). SASSI 2000 User's Manual, Version 3.

Puso, M. (2014). NIKE3D, A Nonlinear, Implicit, Three-Dimensional Finite Element Code for Solid and Structural Mechanics, User Manual . Livermore, CA: Lawrence Livermore National Laboratory.

Ramberg, W., \& Osgood, W. R. (1943). Description of Stress-strain curves by three parameters. National Advisory Committee for Aeronautics, USA (NACA).

Soga, K., \& O'Sullian, C. (2010, December). Modeling of Geomaterials Behavior. Soils and Foundations, 50(6), 861-875.

Solberg, J. M., Hodge, N. A., Ferencz, R. M., \& Puso, M. A. (2014). Diablo Users Manual, Version 1.1. Livermore, CA: Lawrence Livermore National Laboratory.

Solberg, J. M., Hossain, Q., Blink, J. A., Bohlen, S., Mseis, G., \& Greenberg, H. (2013). Development of a Generalized Methodology for Soil-Structure Interaction Analysis Using Nonlinear Time-Domain Techniques - NEAMS Program, DOE Office of Nuclear Energy (NE-41). Lawrence Livermore National Laboratory.

Ueng, T.-S., \& Chen, J.-C. (1992). Computational Procedures for Determining Parameters in Ramberg-Osgood Elastoplastic Model Based on Modulus and Damping versus Strain. Lawrence Livermore National Laboratory. Livermore, CA: Lawrence Livermore National Security.

Wolf, J. P., \& Song, C. (2002). Some cornerstones of dynamic soil-structure interaction. Engineering Structures, 24, 13-28.

Wyatt, D. E., \& Harris, M. K. (2004, December). Overview of the history and geology of the Savannah River Site. Environmental Geosciences, 11(4), 181-190.

Zerfa, F. Z., \& Loret, B. (2003). Coupled dynamic elastic-plastic analysis of earth structures. Soil Dynamics and Earthquake Engineering, 23, 435-454.

Zhang, J., Andrus, R. D., \& Juang, C. H. (2005, April). Normalized Shear Modulus and Material Damping Ratio Relationships. Journal of Geotechnical and Geoenvironmental Engineering, 131(4), 453-464. 